Alma Mater Studiorum - Università di Bologna DEPARTMENT OF ECONOMICS

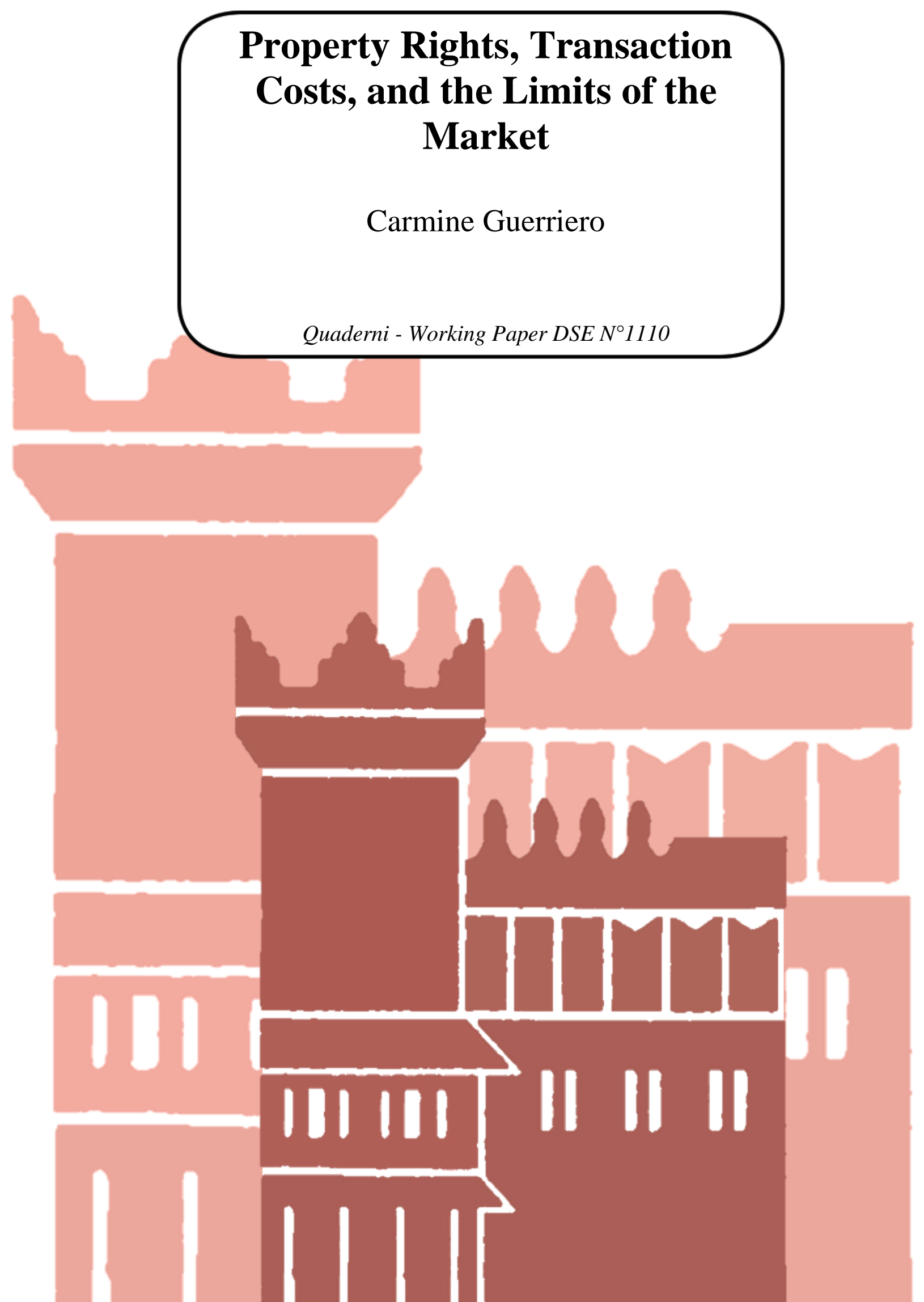




\title{
Property Rights, TransaCtion COSTS, AND THE Limits OF THE MARKET.*
}

\author{
Carmine Guerriero
}

University of Bologna

October 23, 2017

\begin{abstract}
Although the relevance of property rights and transaction costs for trade and innovation are well-known, we still lack a formal framework to think about their origins and interplay. Within trade interactions, fully protecting the original owners' property implies that some high-valuation potential buyers inefficiently refuse to buy it because of transaction costs. When instead property rights are weak, low-valuation potential buyers inefficiently expropriate the original owners' property. The trade-off between these two misallocations entails that property rights will be weaker the larger transaction costs are regardless of whether they are driven by frictions outside the control of traders or determined by the mix of the dispersion in their valuation and either the original owners' market power or their privileged information. A similar conclusion holds true for an upstream firm's property rights on an input necessary to a downstream firm to introduce a new technology and whose cost is random and ex ante non contractible. This time, transaction costs rise with the likelihood of a more productive technology. All these implications survive when a group of traders/innovators has a larger political influence on institutional design and when the disincentive to effort effect of weak property rights is taken into account. Crucially, the model predictions are consistent with the negative effects of proxies for market frictions and failures on measures of the protection of personal, intellectual, and financial property for a panel of 135 countries spanning the 2006-2015 period. Evidence from several identification strategies suggests that these relationships are indeed causal.

Keywords: Property Rights; Transaction Costs; Market Frictions; Market Failures.

JEL classification: D23; L11; P14; Z10.
\end{abstract}

${ }^{*}$ I would like to thank Andy Hanssen, Oliver Hart, Raffaella Paduano, and Giorgio Zanarone for insightful comments. Address: Strada Maggiore 45, 40125 Bologna, Italy. E-mail: c.guerriero@unibo.it 
"Whenever transactions [...] are very expensive, [...] coercion is inherent [and] society will pick the entitlement it deems favorable to the general welfare" [Calabresi and Melamed 1972, p. 1101].

"As soon as the land of any country has all become private property, the landlords, like all other men, love to reap where they never sowed, and demand a rent even for its natural produce" [Smith 1976, p. 67].

\section{Introduction}

Albeit overwhelming evidence shows that strong property rights foster trade and innovation, only recently economists have begun to study the determinants of this institution by looking at the trade-off between the dispersed coercive power in a state of anarchy and the predation by a central enforcement authority (Besley and Ghatak, 2010). Here, I qualify these contributions by incorporating into the economics literature the key insight proposed by a well-known legal scholarship (Calabresi and Melamed, 1972) and, notably, that incomplete property rights can be efficient when transaction costs impede economic activities.

To characterize the trade-off between inefficient exclusion from trade/innovation and expropriation guiding property rights selection, I study both the possibly consensual exchange of economic value between its original owner and a potential buyer and a downstream firm's choice of whether to produce in-house through an old technology or to adopt a new one necessitating an upstream firm's input. In the former case, I build on Guerriero (2016a), and I study a society equally split into original owners, who have the same valuation for the only good in the economy, and potential buyers, who are instead endowed with heterogeneous valuations. The former are randomly matched to the latter by an intermediation technology that allows each potential buyer to either obtain the good via consensual transfer by paying the original owner's valuation and bearing socially wasteful transaction costs or expropriate it at no cost. I define property rights as the probability that an expropriated good is given back to its original owner. When property is fully protected, some potential buyers with valuation higher than that of the original owners are inefficiently excluded from trade due to transaction costs. When instead the protection of property is weak, low-valuation potential buyers inefficiently expropriate original owners. The trade-off between these two misallocations en-

tails that the protection of property, and thus the size of the market, will be more limited the 
larger transaction costs are, regardless of whether the latter are driven by frictions outside the control of traders - e.g., financial inefficiencies - or endogenously determined by the mix of the dispersion in the traders' valuations and either the original owners' market power or their privileged information. ${ }^{1}$ I reach similar conclusions when I turn to investment interactions and I study a society equally split into randomly matched downstream and upstream firms. The new technology requires the provision by the upstream firm of an input whose random cost is realized after the downstream firm has borne an upfront expense. While both costs and the firms' payoffs are observable, unverifiable, and ex ante non contractible, only the cost of the input is ex post contractible. Without loss of generality in particular, I maintain that after the preliminary phase the upstream firm has all the bargaining power and so tries to hold-up his match by asking the high-cost realization. The downstream firm can then either accept to pay the inflated cost, switch to the old technology, or turn to the legal system. In the last case, the payoffs are determined by the upstream firms' property rights, which capture now the odds with which the downstream firm must accept the high cost. This assumption squares with the idea that courts exploit unverifiable information to favor the party they prefer regardless of the contract terms (Gennaioli, 2013). When the protection of property is strong, the risk of being held-up discourages the downstream firms from innovating. When instead the upstream firms are only weakly protected, low-productivity downstream firms inefficiently exploit the input. Balancing these two misallocations entails that the protection of property rights (size of the market) will be weaker (larger) the greater incomplete contracting costs are, i.e., the higher is the probability of low-cost realization.

Crucially, all the model implications survive when a group of traders/innovators has a larger political influence on institutional design and when the disincentive to effort effect of weak property rights is taken into account, and they apply to a wider range of cases. To elaborate on the last point, the legal expropriation by a potential buyer (downstream firm) is strategically similar to a condoned squatting of either a land or a building, the compulsory licensing granted to an intellectual property infringer, a majority stockholder's legal capacity

\footnotetext{
${ }^{1}$ Then, transaction costs result from the transfer of property rights. A broad law and economics tradition brands this definition as inconsistent with the Coase theorem, which would imply that transaction costs are instead those of "establishing and maintaining property rights" [Allen 1999, p. 898]. Nonetheless, ex-post misallocation and not the incentives to protect property and inquire about title is the dimension key for institutional design if both prices and expropriation are endogenous (Dari-Mattiacci and Guerriero, 2015).
} 
to tunnel creditors' and minority shareholders' resources out of a firm, and the discretion of a principal to lawfully segment a market (an agent's power to successfully breach a contract).

To evaluate the central model predictions, I analyze a panel of 135 countries for which the Executive Opinion Survey_EOS, hereafter-run by the World Economic Forum report measures of the protection of personal, intellectual, and financial property and proxies for transaction costs between 2006 and 2015 (see table 1). The EOS is the longest-running survey of the opinions of business leaders on a broad range of topics for which statistics are unreliable, outdated, or nonexistent (WEF, 2015). ${ }^{2}$ Starting with the metrics of property rights, I consider three indicators ranging between one and seven and gaging respectively the protection of generic property including financial assets - i.e., Property-Rights, the defense of intellectual property rights including anti-counterfeiting measures-i.e., Intellectual-Property, and the safeguard of the interests of minority shareholders, i.e., Shareholders-Protection (see table 2 for the definition and sources of these and the remaining variables used in the present study). Being these rights typically assigned to the downstream firms providing the main productive resources [Burk and McDonnel 2007, p. 594], the three aforementioned indexes constitute an inverse (direct) metrics of the property rights of the upstream (downstream) firms. The maps in figure 1 visualize the strong correlation among these three measuresnowhere lower than 0.81 - and their sizable variation across countries. To draw these maps, I averaged each variable over time, and then I divided the range of each average into four equal intervals. In the empirical test instead, I use the continuously measured yearly variables. Furthermore, I document in the Internet appendix that the evidence remains essentially the same when I consider objective regulation-based measures of property rights and in particular the length of adverse possession of personal property and the investor protection index developed by the Doing Business project. ${ }^{3}$ Turning to the proxies for transaction costs, I consider measures of the severity of both market frictions-i.e., excessive regulation and financial inefficiencies - and failures, i.e., lack of the competitiveness of corporate activity, lemons-type distortions, and incomplete contracting costs due to asset specificities.

\footnotetext{
${ }^{2}$ The 2015 edition gathered more than 14,000 responses in 144 countries (WEF, 2015). I substitute missing observations with the closest data points. This choice is immaterial to the gist of the analysis.

${ }^{3}$ Adverse possession is a form of property rights acquisition such that a possessor becomes the legal owner of a good without the original owner's consent, but by virtue of a sufficiently long, open, continuous, and notorious possession. The relative proxy however has no time variation (Dari-Mattiacci and Guerriero, 2015).
} 
OLS estimates suggest that the protection of personal, intellectual, and financial property is the weakest where market frictions and failures are the largest and asset specificities are the most limited. Albeit consistent with the main model predictions, these results may be capturing reverse causality, may be driven by the confounding effect of omitted variables, or may be attenuated by the error in the measurement of transaction costs.

Accordingly, I pursue three strategies to determine if the correlations I uncover are, in fact, causal. First, I control not only for country and year fixed effects, but also for the development level, inclusiveness of political institutions, level of nonproduced output, external and internal conflicts, and human capital. Considering these observables together leaves the results almost intact. Second, I use insights from Altonji, Elder, and Taber (2005) to calculate how much greater the influence of unobservable factors, relative to observables, would need to be to explain away the negative links between property rights and transaction costs. I find that the influence of unobservables would have to be on average sixty times greater than that of all observables considered together, which seems unlikely. Finally, I devise a 2SLS approach based on the positive dependence of market failures (incomplete contracting costs) on the dispersion in the traders' valuations (likelihood of a more productive technology) foreseen by the model. To elaborate, I document strong negative (positive) firststages between the measures of exogenous transaction costs, the extent of market power, and lemons-type distortions (asset specificities) and proxies for both the availability of the latest technologies and the quality of math and science education. These results are consistent with recent firm-level evidence suggesting that the distance to the technology frontier - and thus the difference in the desirability of old and new products - is smaller in countries endowed with a human capital more apt to absorb ideas and knowledge and in which therefore the likelihood of a more productive technology is larger (Añón Higón et al., 2017). Conditional on all observables, the 2SLS estimates are very similar to the OLS ones, and the validity of the exclusion restriction is vindicated by two extra results. First, the Kleibergen-Paap test always rejects under-identification at the 1 percent or less. Second, the overidentifying restrictions cannot be rejected at a level nowhere lower than 5 percent, and the excluded instruments have no direct role in the semi-reduced form regressions. All in all, this evidence makes it difficult to envision that OLS correlations are spuriously driven by reverse causation, 
a mechanism different from the one I model, or measurement error. Accordingly, I take them as consistent with, if not proving, causality running from transaction costs to property rights.

The present study is strictly related to several strands of literature. First, a legacy of recent contributions shows that weak property rights can be optimal in an endowment economy (Jordan, 2006; Bar-Gill and Persico, 2016; Segal and Whinston, 2016; Arruñada, Zanarone, and Garoupa, 2017). Not only do I extend this result to production economies by clarifying how weak property rights can curb market frictions and partially solve market failures, ${ }^{4}$ but I also highlight the relationships between the latter and either the dispersion in the traders' valuations or the likelihood of a more productive technology. Accordingly, my analysis is also related to a body of research - still in its infancy - on endogenous transaction costs (Dari-Mattiacci, 2012; Barry, Hatfield, and Kominers, 2014). ${ }^{5}$ Finally, Acemoglu and Johnson (2005) focus on the relative importance of protecting property rights and enforcing contracts, whereas I examine the determinants of the trade-off between these two institutional strategies created by the possibility of transferring value without consent. Differently from this contribution moreover, I also emphasize that weak property rights are society's response to the existence of sizable transaction costs and thus their negative correlation with economic outcomes might be partly spurious (see for a similar argument Aghion et al., [2010]).

The paper proceeds as follows. In section 2, I discuss the basic relationships between property rights and transaction costs to motivate my more general model, which I illustrate in section 3. Next, I assess whether these correlations are indeed causal in section 4. Finally, I conclude in section 5, and I gather the proofs, tables, and figures in the appendix.

\section{Property Rights and Transaction Costs}

While all legal systems punish theft and embezzlement and provide remedies for the dispossessed owners, the protection of property against private expropriation is almost never complete as clearly displayed in the maps in figure 1 . When transaction costs are sizable indeed, a private party is often allowed to take someone else's property with or without

\footnotetext{
${ }^{4}$ Albeit based on the same basic model, Guerriero (2016a) focuses instead on the relationship between property rights and the heterogeneity in the potential buyers' valuations and does not consider either the issue of technology adoption or the related problem of identifying the drivers of incomplete contracting costs.

${ }^{5}$ While the former emphasizes the feedback of legal rules on transaction costs, the latter draw a link between transaction costs and how egalitarian is the distribution of the collective gains from Coasean bargaining.
} 
paying compensation (Bouckaert and De Geest, 1995). To cast a first glance at whether this pattern accurately describes also the EOS data, I consider one to seven indexes capturing the severity of financial inefficiencies and the relevance of the market failures analyzed in the model, i.e., market power, lemons-type distortions, and incomplete contracting costs.

Starting with the first one, I consider an index measuring the financial sector difficulties in providing products and services to businesses, i.e., Unavailability-Financing. A value of one suggests that it provides a wide variety, whereas a value of seven implies that it does not provide them at all. For what concerns market power, I employ an index capturing the lack of competitiveness of corporate activity, i.e., Market-Dominance. A value of one suggests that corporate activity is spread among many firms, whereas a value of seven implies that it is dominated by few business groups. Turning to lemons-type distortions, I focus on an index falling with the extent of information used by buyers to make purchasing decisions, i.e., Asymmetric-Information. A value of one suggests that purchases are based on a sophisticated analysis of attributes, whereas a value of seven implies that they are based solely on the lowest price. Finally, I capture asset specificities with a measure of the competitive advantage of the country's companies in international markets, i.e., Asset-Specificities. A value of one suggests that it is represented by low cost labor or natural resources, whereas a value of seven implies that it is constituted by unique products and processes.

Conditional on country and year fixed effects, the partial correlations between the measures of property rights and Unavailability-Financing, Market-Dominance, and AsymmetricInformation (Asset-Specificities) in figures 2 to 4 (figure 5) reveal that there are strong negative (positive) links between the legal protection of the original owners' (downstream firms') property and market frictions and failures (asset specificities), which are based on a sizable within variation and not driven by a handful of abnormal observations. ${ }^{6}$ Columns (2), (3), (5), and (6) of table 3 report estimates of these correlation from regressions obtained from the subsamples for which I observe all the additional controls illustrated in section 4.1.1 and with standard errors allowing for clustering by country. In particular, a one-standard-deviation rise in Unavailability-Financing, Market-Dominance, or Asymmetric-Information (AssetSpecificities) - roughly 1 (0.9) — is associated with about a 0.3(0.4)-standard-deviation-i.e.,

\footnotetext{
${ }^{6}$ My results are similar when I exclude the outliers identified through the Cook's distance (Cook 1977).
} 
around 1 - fall (rise) in the strength of property rights. These coefficients are all significant at 5 percent or better and are coherent with the evidence coming from two alternative one to seven indexes of market frictions and failures (see columns (1) and (4) of table 3). While the former gages the burden of administrative requirements on firms-i.e., Over-Regulation, the latter measures the impact of non-tariff barriers on the ability of imported goods to compete with domestic ones, i.e., Trade-Barriers. More generally, I document in the Internet appendix that the negative (positive) links between the original owners' (downstream firms') property rights and market frictions and failures (asset specificities) survive when the latter are proxied by either the necessity of bribery for the daily activity of firms, their difficulty to obtain a bank loan, the hurdle they face when raising money by issuing shares on the stock market, or the lack of competitiveness of local markets (extent of production sophistication).

Next, I present a model of the design of property rights on exchangeable value and innovation activities rationalizing several legal issues included the evidence discussed so far.

\section{Theory}

I first analyze the case in which transaction costs are driven by frictions outside the control of traders (innovators), and then I turn to characterize the scenario in which they are endogenously determined by the mix of the dispersion in the traders' valuations and either the original owners' market power or their privileged information (the likelihood of a more productive technology and the incompleteness of contracts). Finally, I document that the key model implications survive when the economy becomes "political" and thus someone is excluded from the institutional design (see section 3.3.1) and when the original owners can decide whether to produce or invest in their property (see section 3.3.2).

\subsection{Property Rights and Exogenous Transaction Costs}

Following Guerriero (2016a), I consider a society composed by a mass one of original owners and a mass one of potential buyers, all having linear utility over a good $x$ (see footnote 14 for the risk aversion case). While the original owners value $x$ at $v$, the potential buyers have a valuation $\lambda$ uniformly distributed over $[\underline{\lambda}, \bar{\lambda}]$ with $l \equiv \bar{\lambda}-\underline{\lambda}, \bar{\lambda}>v>\underline{\lambda}$, and $\lambda_{m} \equiv(\bar{\lambda}+\underline{\lambda}) / 2$. I employ the uniform distribution to obtain closed form solutions, but in 
the appendix I show that the results hold under more generic density functions.

Original owners are randomly matched to potential buyers by an intermediation technology allowing the latter to either obtain the good via consensual transfer by paying the former $v$ and bearing positive transaction costs $\alpha$ or expropriate it at no cost. The assumption that expropriation is costless does not bear any loss of generality. ${ }^{7} \alpha$ has no social value and gages inefficiencies like the costs borne by potential buyers to borrow $v$ or those necessary to legalize the transfer and due to bribery, bargaining costs, excessive regulation, or a foreign intermediary's mark-up. ${ }^{8}$ I posit that $\alpha<\min \{v, \bar{\lambda}-v\}$, and I discuss this assumption in footnotes 11,12 , and 13. An expropriated $x$ is returned back with odds $\gamma$, which thus summarizes the legal protection of the original owner's property rights or the odds with which the original owner is protected by a property rule as opposed to $1-\gamma$, which is the chance with which the potential buyer is shielded by a liability rule (Calabresi and Melamed, 1972).

One glaring example of the type of expropriation just discussed is that of an intermediary (agent) selling to a buyer in good-faith a good stolen (embezzled) from an original owner (his principal) at a low price. As happens in the model, then the good is possibly given back to its original owner and the strength of property rights reduces the probability that the buyer consumes. More generally, when the potential buyer directly steals $x$, only with probability $\gamma$ the legal system forces her to hand the good back to its original owner. All in all, then $\gamma$ will be larger the longer the buyer needs to wait before acquiring ownership by adverse possession, the stronger are the remedies in the original owner's hands, and the more effective is public enforcement (Dari-Mattiacci and Guerriero, 2015). The model however applies to a large array of legal instances. First, the good can be envisaged as an input producing a fixed value when transformed via the "old" technology in the hands of the original owners and an uncertain one when the "new" technology is applied by the potential buyers. Second, expropriation can assume the form of the squatting of either a piece of land or a building (Brueckner and Selod, 2009). ${ }^{9}$ Third, the conflict between an original owner and a potential

\footnotetext{
${ }^{7}$ The model implications survive when expropriation entails either an expensive effort or a punishment and if the liability rule prescribes positive damages, provided that these cost are not too large (Guerriero, 2016a). ${ }^{8}$ Notably, the setup I consider can be interpreted as an efficient market maker assigning high-valuation potential buyers to original owners in exchange for the wasteful payment $\alpha$.

${ }^{9}$ The good can be conceived as having a fixed value for the original owner and an uncertain one for the state as in the instances regulated by "partial taking" law. Then, the state pays severance damages $(1-\gamma) v$ to the original owner to compensate a partial expropriation by the potential buyer (Sackman at al., 2013).
} 
buyer can be reinterpreted as the one involving the creator of an intellectual property and an infringer with $1-\gamma$ being the chance of either exhaustion of the related rights or compulsory licensing (Ghosh, 2014; Bond and Saggi, 2017). Fourth, the same tension is isomorphic to that between a creditor/minority shareholder and a majority stockholder who can tunnel resources out of the firm through a complaisant management (Johnson et al., 2000). Finally, the very same interaction is strategically similar to that setting an agent against a principal in a segmented labor, financial or housing market with $1-\gamma$ gaging the principal's capacity to lawfully operate in the secondary segment (Piazzesi, Schneider, and Stroebel, 2017).

At time $t_{0}, \gamma$ is chosen to maximize the social welfare, which is the sum of the original owners' and potential buyers' utilities. At time $t_{1}$, individuals learn who they are and, thus, their valuation. At time $t_{2}$, individuals are matched by the intermediation technology. Finally at time $t_{3}$, any expropriated $x$ is given back to its original owner with probability $\gamma$.

In evaluating the foregoing, two remarks should be stressed. First, an alternative instrument in the hands of society is to decrease $\alpha$. This policy reduces market distortions leading to complete property rights (see footnotes 11 and 12), but it is very costly to implement because of political imperfections (Besley and Ghatak, 2010) and the opposition of those agents who gain from larger transaction costs (see section 3.2 and Barry, Hatfield, and Kominers, [2014]). Second, the model implication are unaffected when the original owners have heterogeneous valuations and the traders can bargain over the price (Guerriero, 2016a).

\subsubsection{Equilibrium}

A potential buyer buys if her valuation $\lambda$ net of the purchasing costs $v+\alpha$ is greater than her expected payoff from expropriation $(1-\gamma) \lambda$ or $\lambda \geq \hat{\lambda} \equiv \frac{v+\alpha}{\gamma} \cdot{ }^{10}$ When selecting the optimal property rights level $\gamma^{*},{ }^{11}$ society then maximizes the strictly concave function

$$
\int_{\hat{\lambda}}^{\bar{\lambda}} \frac{\lambda-\alpha}{l} d \lambda+\int_{\underline{\lambda}}^{\hat{\lambda}} \frac{(1-\gamma) \lambda+\gamma v}{l} d \lambda
$$

\footnotetext{
${ }^{10}$ Provided that only one good can be consumed, the results continue to stand even if those $x$ that are purchased can be expropriated before consumption since all those willing to expropriate have already done it.

${ }^{11}$ The objective function in equation (1) is strictly concave for $\alpha<v$. Should this inequality fail, $\gamma^{*}$ will be $1(0)$ for $v<\lambda_{m}$ if the social welfare is larger at $1(0)$ than it is at $0(1)$ or whenever $(v+\alpha)^{2}-2(\alpha \bar{\lambda}+v \underline{\lambda})+\underline{\lambda}^{2}>$ $(\leq) 0$. This last inequality is more difficult to satisfy the larger $\alpha$ is because of the hypothesis $v+\alpha<\bar{\lambda}$.
} 
for $\hat{\lambda}<\bar{\lambda}$ or $\gamma^{*} \in\left(\frac{v+\alpha}{\bar{\lambda}}, 1\right]$ and the full expropriation social welfare $(1-\gamma) \lambda_{m}+\gamma v \equiv W^{F E}$ whenever $\hat{\lambda} \geq \bar{\lambda}$ and therefore all potential buyers prefer to expropriate.

Switching from complete to incomplete property rights-i.e., from $\gamma^{*}=1$ to $\gamma^{*}<1-$ has three effects: 1 . it saves $\alpha$ at the cost of misallocating $x$ with probability $\gamma^{*}$ for the $v+\alpha \leq \lambda<\hat{\lambda}$ matches; 2 . it avoids misallocation with probability $1-\gamma^{*}$ for the $v \leq \lambda<v+\alpha$ matches by expanding the consumption set of the potential buyers; 3 . it misallocates $x$ with probability $1-\gamma^{*}$ for the $\lambda<v$ matches. While this last effect is negative, the sum of the first two is positive, provided that $\alpha$ is not too small. ${ }^{12}$ For $\hat{\lambda}<\bar{\lambda}$, optimal property rights are uniquely defined by the necessary and sufficient first-order condition

$$
-2 \frac{d \hat{\lambda}}{d \gamma}\left(\gamma^{*} \hat{\lambda}-\gamma^{*} v-\alpha\right)-\left(\hat{\lambda}^{2}-\underline{\lambda}^{2}\right)+2 v(\hat{\lambda}-\underline{\lambda})=0 \leftrightarrow\left(\gamma^{*}\right)^{2}=\frac{v^{2}-\alpha^{2}}{\underline{\lambda}(2 v-\underline{\lambda})}
$$

Equation (2) implies that a rise in $\gamma$ has a marginal effect, which is positive, and an inframarginal effect $\int_{\underline{\lambda}}^{\hat{\lambda}} \frac{v-\lambda}{l} d \lambda=-\frac{(\hat{\lambda}-\underline{\lambda})(\hat{\lambda}+\underline{\lambda}-2 v)}{2 l}$, which can be negative only if $v<\lambda_{m}$. For $v \geq \lambda_{m}$ then, optimal property rights are complete since also $W^{F E}$ rises with $\gamma$. For $v<\lambda_{m}$ instead, $W^{F E}$ falls with $\gamma$ and a $\gamma^{*} \leq 1$ is possible. It equals either the level defined by equation (2) or 0 depending on which of the two maximizes the social welfare. The latter is more likely the case the larger $\alpha$ is. ${ }^{13}$ Moreover, an interior $\gamma^{*}$ falls with $\alpha$ (see figure 2).

Intuitively, a rise in $\alpha$ has the infra-marginal effect of reducing the potential buyer's payoff for all the $\lambda \geq \hat{\lambda}$ matches and the marginal effect of raising $\hat{\lambda}$ and thus misallocating goods otherwise earmarked to high-valuation potential buyers with probability $\gamma^{*}$. Both effects call for weaker property rights. Proposition 1 rephrases this idea: ${ }^{14}$

Proposition 1: Optimal property rights $\gamma^{*}$ weakly fall with the transaction costs $\alpha$.

Proposition 1 is not only consistent with the preliminary evidence discussed in section 2 and the more in depth analysis in section 4, but it also sheds light on several institutionalized cases of incomplete property rights. First, it rationalizes the post-war condoning of power

\footnotetext{
${ }^{12} \overline{\text { Precisely, if } \alpha^{2}>(1-\gamma) v^{2} \text {. Moreover, } \gamma^{*}}<1$ whenever $\alpha>v-\underline{\lambda}$, which can be given my assumptions. ${ }^{13}$ The exact condition is $\gamma^{*}(\bar{\lambda}-v)>\alpha$, which is true for the lowest interior $\gamma^{*}=(v+\alpha) \bar{\lambda}^{-1}$ if $\alpha<\bar{\lambda}-v$.

${ }^{14}$ If risk-averse, the traders who gain an expected utility lower than that prevailing under the certain scenario of full property rights incur also a loss $u$. Since all original owners (potential buyers) weakly prefer complete (incomplete) property rights, a rise in risk aversion is isomorphic to a fall in $v$ and thus induces a weakly lower $\gamma^{*}$. Indeed, an increase in $v$ has the infra-marginal effect of boosting the original owners' payoff when property rights are protected and the marginal effect of raising $\hat{\lambda}$. Both patterns imply a higher $\gamma^{*}$.
} 
thefts by Indian farmers. In fact, despite its annual cost is around 1.5 percentage points of the 2012 GDP, local politicians have been strenuously defending it by asserting that collecting the electricity invoices, which are mainly constituted by billing costs, would destroy subsistence farming (Charnoz and Swain, 2012). Second, the cost of eviction or the inability to provide a sufficient supply of housing because of regulatory requirements and speculative land-holding are the most recurring justifications to the tolerance towards the roughly 40 percent share of private lands invaded in developing countries and the two billion squatters estimated around the world (Brueckner and Selod, 2009). Third, exhaustion of intellectual property rights has been mainly implemented in high-transaction costs developing countries (Ghosh, 2014), whereas the Article 31 of the TRIPS agreement allows the participants to impose compulsory licensing if the commercial terms for a voluntary license are "unreasonable" (Bond and Saggi, 2017). Finally, Piazzesi, Schneider, and Stroebel (2017) conclude that financial costs explain 14 percent of the price gap between first and secondary housing market segments.

\subsection{Property Rights and Endogenous Transaction Costs}

Next, I evaluate several key instances of endogenously determined transaction costs.

\subsubsection{Property Rights and Market Power}

Following Guerriero (2016a), I consider the case in which the intermediation technology is in the hands of the original owners and $\alpha$ is the mark-up on their valuation $v$. They select it between $t_{1}$ and $t_{2}$ by maximizing the sum of the expected profits and the expected payoff from consuming $x$ when handed back, i.e., $\frac{(v+\alpha)(\bar{\lambda}-\hat{\lambda})}{l}+\gamma^{*} v \frac{(\hat{\lambda}-\underline{\lambda})}{l}$ for $\frac{v+\alpha}{\gamma^{*}}=\hat{\lambda}<\bar{\lambda}$ and $\gamma^{*} v$ otherwise. Then, $\alpha^{*}$ can be positive only for $\hat{\lambda}<\bar{\lambda}$ when it equals $\alpha^{*}=\frac{\gamma^{*}(\bar{\lambda}+v)}{2}-v$ and rises with the strength of property rights, which in turn increases the original owners' payoff regardless of whether transfers are consensual. A rise in $\gamma^{*}$ reduces instead the potential buyers' payoff from expropriating and, through its positive impact on $\alpha^{*}$, their utility from

buying $x$. Because of the linearity of preferences, the two effects cancel out and $\frac{d \hat{\lambda}}{d \gamma^{*}}=0$ (see the Appendix). Since $\alpha$ is now a transfer, $\gamma^{*}<1$ if the distortions in the potential buyers' demand are sizable. Being $\hat{\lambda}=\frac{\bar{\lambda}+v}{2}<\bar{\lambda}$, society maximizes the linear function

$$
\int_{\hat{\lambda}}^{\bar{\lambda}} \frac{\lambda}{l} d \lambda+\int_{\underline{\lambda}}^{\hat{\lambda}} \frac{(1-\gamma) \lambda+\gamma v}{l} d \lambda
$$


whose derivative with respect to $\gamma$ for $v<\lambda_{m}$ is negative for $\alpha^{*}>(2 v-\underline{\lambda}) \gamma^{*}-v$ or $\bar{\lambda}+2 \underline{\lambda}>3 v$ and positive otherwise. Then, $\gamma^{*}$ possibly jumps from 0 to 1 as $\alpha^{*}$ becomes sufficiently small. For $\gamma^{*}=1, \alpha^{*}=\frac{(\bar{\lambda}-v)}{2}$ and the mark-up increases with the difference between high-valuation potential buyers' and original owners' valuation. Again, optimal property rights must be complete if $v \geq \lambda_{m}$. Proposition 2 takes stock of this analysis:

Proposition 2: The optimal property rights level $\gamma^{*}$ weakly decreases with the mark-up $\alpha^{*}$, which in turn is larger the higher the dispersion in the traders' valuations $\bar{\lambda}-v$ is.

Proposition 2 not only rationalizes some of the results discussed in sections 2 and 4, but it also helps make sense of growing evidence on the weakness of property rights on renewable resources in the presence of market power. Common access to the fishing harvest together with individual transferable quotas indeed is more often observed in Nova Scotia and New Zealand where the fishermen's market power is the strongest (Croutzet and Lasserre, 2017). ${ }^{15}$

\subsubsection{Property Rights and Lemons-type Distortions}

As noticed by Hasen and McAdams (1997), "theft may avoid the "lemons" problem." Following Guerriero (2016a), I maintain here that the original owners have private information on $v$, which is drawn from an uniform distribution with support $[0, \bar{\lambda}]$ and correlated with the valuation of the potential buyers. In particular, $\Delta / 2$ of them value $x$ at $\theta v, 1-\Delta>0$ of them have valuation $\alpha v$, and the remainder gain from consuming $x$ a payoff $v / \theta$ with $\theta>2>\alpha>1$. Here, $\theta$ gages the polarization of the potential buyers' preferences, $\alpha$ covers the role that exogenous transaction costs have in the basic setup and represents a measure of the difference between the payoff of the middle-valuation potential buyers and the valuation of the original owners, and a rise in $\Delta$ constitutes a mean-preserving spread of the $\lambda$ distribution. These three parameters emphasize the impact of lemon-type distortions on allocative efficiency in the regime $L$. To illustrate, middle and low-valuation potential buyers expropriate (do not consume) if $\gamma^{*}<(=) 1$ since the expected value of $x$ is $p_{L} / 2$ at the exogenous price $p_{L}$. Original owners indeed sell only if $v \leq p_{L}$. High-valuation potential buyers buy (expropriate) if $\gamma^{*} \geq(<) \frac{2}{\theta}$, and society maximizes the linear function

\footnotetext{
${ }^{15}$ Focusing on the fishing industry, Croutzet and Lasserre (2017) also show that the strength of the property rights on renewable resources should fall with the elasticity of output to effort and rise with the price elasticity of demand, the number of firms, and the difference between input and output values.
} 


$$
\theta \lambda_{m} \frac{\Delta}{2}+(1-\Delta)\left[(1-\gamma) \alpha \lambda_{m}+\gamma \lambda_{m}\right]+\left[(1-\gamma) \frac{\lambda_{m}}{\theta}+\gamma \lambda_{m}\right] \frac{\Delta}{2}
$$

for $\gamma^{*} \geq \frac{2}{\theta}$ and $(1-\gamma)\left[(1-\Delta) \alpha+\frac{\theta^{2}+1}{\theta} \frac{\Delta}{2}\right] \lambda_{m}+\gamma \lambda_{m}$ otherwise. Hence, the derivative of society's problem with respect to $\gamma$ is positive for $\gamma^{*} \geq \frac{2}{\theta}$ and both $1-\Delta$ and $\alpha$ sufficiently small and it is negative otherwise. Intuitively, as the share of middle-valuation potential buyers for which $x$ will be misallocated under complete property rights becomes less important because of a rise in heterogeneity, $\gamma^{*}$ jumps from 0 to 1 for $\alpha$ small. Similarly, a sufficiently large rise in lemons-type distortions $\alpha$ induces a decrease in the optimal property rights level from 1 to 0 for $\Delta$ small. Proposition 3 recaps the analysis of this section:

Proposition 3: Optimal property rights $\gamma^{*}$ weakly fall with the lemon-type distortions $\alpha$, which in turn constitute a measure of the dispersion in the traders' valuations.

Proposition 3 not only clears up some of the evidence illustrated in sections 2 and 4, but it also helps explain recent stylized facts about sharing economies. In particular, Lee (2016) builds on 2008 data on BitTorrent private-network file sharing activity and album sales to conclude that the former has no impact (a positive effect) on top(mid)-tier artists' sales for which asymmetric information on perceived talent is the least (most) detrimental.

\subsubsection{Property Rights and Incomplete Contracting Costs}

Setup.-Consider now a mass one of upstream firms and a mass one of downstream firms. The latter can employ two technologies to produce $x$. The "old" one does not necessitate any input from the upstream firm, and it produces one unit of output of value $\delta \lambda$ with $\delta<1$, $\lambda$ uniformly distributed over $[\underline{\lambda}, \bar{\lambda}], l \equiv \bar{\lambda}-\underline{\lambda}, \bar{\lambda}>v>\underline{\lambda}$, and $\lambda_{m} \equiv(\bar{\lambda}+\underline{\lambda}) / 2$. The "new" technology instead delivers one unit of output of value $\lambda$ and requires first an upfront payment $v$ by the downstream firm, and then the provision by the upstream firm of an input whose $\operatorname{cost} c$ is realized after the preliminary phase and equals 0 with probability $0<\alpha<1$ and $(1-\delta) \lambda$ otherwise. $^{16}$ While both costs and the firms' payoffs are observable, unverifiable, and ex ante non contractible, only the cost of the input is ex post contractible. Without loss of generality in particular, I maintain that after the preliminary phase the upstream firm has

\footnotetext{
${ }^{16}$ Should the low cost be $\mu<(1-\delta) \lambda$, the social welfare will equal $\alpha \int_{\hat{\lambda}}^{\bar{\lambda}} \frac{\lambda-v}{l} d \lambda+(1-\alpha) \int_{\hat{\lambda}}^{\bar{\lambda}} \frac{\lambda-v-\mu}{l} d \lambda+\int_{\underline{\lambda}}^{\hat{\lambda}} \frac{\delta \lambda}{l} d \lambda$ with $\hat{\lambda} \equiv \frac{v+\gamma \alpha}{1-\delta} \geq \tilde{\lambda}$ and the whole argument of this section will go through unchanged.
} 
all the bargaining power. Hence, the cost uncertainty creates with odds $\alpha$ an "appropriable quasi-rent" $(1-\delta) \lambda$, which is larger the more productive the new technology is relative to the old one, and in turn the incentive for the upstream firm to always claim that $c=(1-\delta) \lambda$ (Barzel, 1989). ${ }^{17}$ Only with probability $\gamma$ yet, the upstream firm is legally allowed to charge the high cost. Hence, $\gamma$ captures the strength of the upstream firm's property rights on his input relative to the power of the downstream firms' property rights on $x$. When the input is an idea or know-how for instance, $v$ might be seen as the expenses supported by the downstream firm to let the upstream firm understand how to incorporate his input in the old production process, $c$ is the cost of providing the input, and $\gamma$ can be interpreted as the probability that, in a lawsuit for breach of contract launched by the downstream firm, a court allows the upstream firm to charge for the input provision $(1-\delta) \lambda$ instead of 0 . This setup squares with the idea that courts display personal biases and arbitrarily evaluate the evidence when certain states are hard to verify and so subject to interpretation (Gennaioli, 2013). Then, the parameter $\gamma$ can also be seen as the share of pro-upstream firm courts.

The timing of the institutional and economic activities is as follows. At time $t_{0}, \gamma$ is chosen to maximize the social welfare, which is the sum of upstream and downstream firms' payoffs. At time $t_{1}$, each downstream firm selects her preferred technology. If the old one is employed, production is immediate, otherwise the downstream firm is matched to an upstream one and the two firms sign a contract establishing that in time $t_{2}$ the latter has residual rights on his input and all bargaining power at renegotiation (Grossman and Hart, 1986). At time $t_{2}$, first the preliminary phase is concluded, then the upstream firm makes a take-it-or-leave-it request to the downstream firm. Next, the latter can either accept, reject and turn to the old technology, or reject and exploit the available legal remedies. In this last case, the downstream and upstream firms' payoffs are determined by the prevailing $\gamma$.

Interpretation.-The parameter $\alpha$ should be seen as a general measure of incomplete contracting costs. To elaborate, the conflict between upstream and downstream firms resembles again that between a creditor/minority shareholder and a majority stockholder who can tunnel value out of the firm through a complaisant management asserting that investing

\footnotetext{
${ }^{17}$ Under the usual assumption of Nash bargaining indeed, the upstream firm will require for $c=0$ an input price equal to $(1-\delta) \frac{\lambda}{2}$. Then, the new technology will be adopted for all $\lambda$ larger than $\frac{2 v}{\alpha(1-\delta)}$, which is inefficiently higher than $\tilde{\lambda}$, and the gist of the whole analysis will continue to hold true.
} 
in a new activity needs resources that are ex ante non contractible. Similarly, the contrast between the two firms is strategically equal to the interaction between a principal and an agent who can breach their contract by claiming that the ex ante non contractible cost of using a new technology is $(1-\delta) \lambda$ instead of being 0 (Ganglmair, 2017).

Equilibrium.-For $\gamma^{*}=1$, the downstream firm obtains $\delta \lambda-v$ with the new technology and $\delta \lambda$ with the old one. She prefers the latter and the social welfare is $\int_{\underline{\lambda}}^{\bar{\lambda}} \frac{\delta \lambda}{l} d \lambda$, which is inefficiently lower than that under the ex ante efficient equilibrium prescribing innovation and a downstream's (upstream's) expected payoff of $\alpha \lambda+(1-\alpha) \delta \lambda(0)$ for $\lambda \geq \tilde{\lambda} \equiv \frac{v}{\alpha(1-\delta)}$.

Incomplete property rights solve this hold-up failure since they allow the downstream firm to obtain from adopting the new technology $\lambda-v$ with probability $1-\gamma$ and $\delta \lambda-v$ otherwise and the upstream firm to get from the input provision the expected loss $(1-\alpha)(1-\delta) \lambda$ with probability $1-\gamma$ and the expected gain $\alpha(1-\delta) \lambda$ otherwise. Hence, the downstream firm will prefer the new technology for $\lambda \geq \hat{\lambda} \equiv \frac{v}{(1-\delta)(1-\gamma)}$, and the upstream firm will produce only if property rights are sufficiently strong or $\frac{\gamma^{*}}{\left(1-\gamma^{*}\right)} \geq \frac{1-\alpha}{\alpha} \leftrightarrow \gamma^{*} \geq 1-\alpha$. For $\gamma^{*} \geq 1-\alpha$ and $\hat{\lambda}<\bar{\lambda}$, society maximizes the following strictly concave function

$$
\alpha \int_{\hat{\lambda}}^{\bar{\lambda}} \frac{\lambda-v}{l} d \lambda+(1-\alpha) \int_{\hat{\lambda}}^{\bar{\lambda}} \frac{\delta \lambda-v}{l} d \lambda+\int_{\underline{\lambda}}^{\hat{\lambda}} \frac{\delta \lambda}{l} d \lambda
$$

which decreases with $\gamma$ for $-\frac{d \hat{\lambda}}{d \gamma}[\alpha \hat{\lambda}+(1-\alpha) \delta \hat{\lambda}-v-\delta \hat{\lambda}]=-\frac{v^{2}(\alpha-1+\gamma)}{(1-\delta)(1-\gamma)^{3}} \leq 0$ or if $\gamma \geq 1-\alpha$. To elaborate, a rise in $\gamma \geq 1-\alpha$ has the welfare decreasing marginal effect of shrinking the set of matches for which the downstream firm adopts the new technology. Yet, a $\gamma^{*}$ weakly larger than $1-\alpha$ is necessary to push the upstream firm to participate in the production process. Therefore, $\gamma^{*}=1-\alpha$. In other words, the larger the odds $\alpha$ of a positive appropriable quasirent are and thus the more severe asset specificities are, the lower $\gamma^{*}$ should be to convince the downstream firm to adopt the new technology and the upstream firm to provide his input. ${ }^{18}$ Crucially, the latter is indifferent between charging as input price the expected cost and holding-up the downstream firm given $\gamma^{*}$. By assuming that if indifferent he selects the former strategy, then the setup produces no hold-up in equilibrium. For $\alpha$ large moreover, the

\footnotetext{
${ }_{18}$ This incentive will be unnecessary, should the cost be certain. In this case, full property rights will contemporaneously solve the hold-up failure and assure the upstream firm's participation constraint.
} 
welfare under incomplete property rights and innovation is larger than that with $\gamma^{*}=1$ and without innovation. The latter also describes the scenario in which $\hat{\lambda} \geq \bar{\lambda} \leftrightarrow v \geq \alpha(1-\delta) \bar{\lambda}$. Proposition 4 summarizes the main conclusions of this section:

Proposition 4: Optimal property rights $\gamma^{*}$ fall with the incomplete contracting costs $\alpha$, which in turn measure the likelihood that the new technology is more productive.

Recognizing that both parties should be incentivized to foster technological diffusion, proposition 4 entails that, differently from Grossman and Hart (1986), Hart and Moore (1990), and Williamson (2010), asset allocation is optimized by alternatively leaving residual claimant each party. This result has key ramifications for the theory of the firm. ${ }^{19}$

More generally, the findings of this section are not only coherent with some of the estimates discussed in sections 2 and 4, but they also help make sense of anecdotal evidence on the positive link between the strength of the downstream firm's intellectual property rights - a high $1-\gamma^{*}$ - and the severity of asset specificities. In particular, Burk and McDonnel (2007) document that stronger and easier to obtain downstream firm's intellectual property rights - i.e., trade secrecy and copyright instead of patents - are typically granted whenever asset specificities are particularly severe, i.e., technological businesses, such as the software industry, and the entertainment industries. ${ }^{20}$ Furthermore, these remedies allow the downstream firm to impose on her employees and upstream partners non-disclosure agreements, work-for-hire provisions, and non-compete clauses reducing their ability to exploit proprietary information, i.e., a low $\gamma^{*}$ (Burk and McDonnel, 2007). "From the standpoint of employee incentive [indeed], trade secrecy [and copyright are the] most expensive method of protection [since they include] forms of intellectual capital most likely to become commingled [...] from the skills or knowledge of an employee" [Burk and McDonnel 2007, p. 609].

\subsection{Robustness Checks}

In this section, I document the robustness of the main model implications to two key alternative assumptions, i.e., the possibility that part of the population is excluded from

${ }^{19}$ Guerriero (2017) shows that the model prediction survives if the firms can choose whether to vertically integrate and that this happens more often when asset specificities (property rights) are more severe (stronger).

${ }^{20}$ First, trade secrecy and copyright arise spontaneously, upon fixation of a creative work in a tangible medium of expression, whereas patent are granted only upon the disclosure of the claimed invention (Burk and McDonnel, 2007). Second, they receive a longer protection, i.e., respectively perpetual monopoly and the author's life plus 50 to 100 years rather than the 20 years of patent protection (Burk and McDonnel, 2007). 
institutional design and the possibility for the original owners to decide whether to produce the good or to invest on it before trading (see the appendix for the relative proofs).

\subsubsection{The Political Economy of Property Rights Protection}

Thus far, I have examined the design of property rights on exchangeable value under a perfect veil of ignorance, behind which everybody is identical, and the choice of property rights on innovation by downstream and upstream firms with equal size and in turn political power. Reality is however much less ideal. To evaluate the positive side of property rights protection, I consider a situation in which the group of agents selecting $\gamma$ either knows his future role in the economy or is endowed with important inputs and so can exclude the rest of the population from the social welfare maximization (Alesina, Aghion, and Trebbi, 2004). It seems natural to think of these "insiders" as the original owners and the potential buyers with moderate valuations. This approach incorporates into the model the idea put forward by a growing literature on endogenous lobbying that the groups actively participating in policy-making and shaping reforms are those most affected by them (Felli and Merlo, 2006; Guerriero, 2016b). Here, these are original owners and middle-valuation potential buyers.

In the case of exogenously determined transaction costs then, $\gamma^{*}$ maximizes $\int_{\hat{\lambda}}^{\bar{\lambda}} \frac{\lambda-\alpha}{l} d \lambda+$ $\int_{\underline{\lambda}+\epsilon}^{\hat{\lambda}} \frac{(1-\gamma) \lambda+\gamma v}{l} d \lambda+\frac{\gamma v \epsilon}{l}$ for $\hat{\lambda}<\bar{\lambda}$ and $W^{F E}-(1-\gamma) \frac{\epsilon^{2}+2 \epsilon \underline{\lambda}}{2 l}$ otherwise when the excluded potential buyers have valuation lower than $\underline{\lambda}+\epsilon$ and $\epsilon$ not too large. Comparing this objective function with that in equation (1) suggests that $\gamma^{*}$ still falls with $\alpha$ for $\epsilon$ not too large, but it is set inefficiently high, e.g., Zamindari system of taxation allowing Indian landowners to evict evading tenants who were often more productive (Besley and Ghatak, 2010). If instead to be excluded are the potential buyers whose valuation is higher than $\bar{\lambda}-\epsilon, \gamma^{*}$ decreases with $\alpha$ for $\epsilon$ small and equals (is higher than) the $\gamma^{*}$ found in the basic setup if interior (otherwise). When instead the transaction costs are driven by market power, $\alpha^{*}$ continues to be determined as in section 3.2.1 and thus a rise in $\gamma$ still has only an infra-marginal effect on society's objective function. As a result, equation (3) implies that the analysis is unchanged when high-valuation potential buyers are excluded from the institutional design and that $\gamma^{*}$ is set too high and falls with $\alpha^{*}$ for $\epsilon$ small when instead low-valuation potential buyers are kept out. Similarly, in the scenario of transaction costs determined by lemon- 
type distortions, a gaze at equation (4) suggests that equilibrium property rights are again inefficiently high and decrease with $\alpha$ provided that $\epsilon$ is not too large. Finally, a glance at equation (5) clarifies that excluding a sufficiently small group of either high- or low- $\lambda$ downstream firms from the institutional design does not affect at all the equilibrium when the transaction costs are shaped by incomplete contracting inefficiencies.

\subsubsection{The Disincentive to Effort Effect of Weak Property Rights}

Production.-As highlighted in section 1, all the other contributions documenting that weak property rights can be optimal focus on endowment economies. Here, I prove that the mechanisms illustrated in sections 3.1, 3.2.1, and 3.2.2 survive when production is introduced in the theoretical framework. This time, original owners decide between $t_{1}$ and $t_{2}$ whether to produce $x$ at the cost $\kappa<v$. Therefore, there is no production for $\gamma^{*}=0$ and $\hat{\lambda} \geq \bar{\lambda}$, but there can be when the original owners' expected utility is positive for $\gamma^{*}>0$ and so $\hat{\lambda}<\bar{\lambda}$. To elaborate, the original owners' expected utility increases with $\gamma^{*}$, and therefore there is a $\tilde{\gamma}$ such that $x$ is produced only if $\gamma^{*} \geq \tilde{\gamma}$. Since production creates value also for the potential buyers, society always selects the maximum $\hat{\gamma}$ between $\tilde{\gamma}$ and $\gamma^{*}$ for $\kappa$ not too large. In the most interesting case of endogenous transaction costs finally, $\tilde{\gamma}$ weakly decreases with $\alpha$ for $\bar{\lambda}$ sufficiently large and $v$ not too small compared to the transaction costs $\alpha$. This last comparative statics leaves qualitatively unaffected the main model testable implication.

Investment.-The standard "security" argument for strong property rights claims that expropriation induces a disincentive to invest (Besley and Ghatak, 2010). To understand how the intuition affects the basic results, I analyze a regime $I$ envisioning an investment possibly implemented by the original owners between $t_{1}$ and $t_{2}$ at the cost $\zeta<v$ and raising their valuation $v$ and those of the potential buyers $\lambda$ to respectively $v(1+\rho)$ and $\lambda(1+\rho)$ with $\rho>0 .{ }^{21}$ Accordingly, this setup is similar to the instance of a production economy.

When transaction costs are exogenous, original owners invest only if $\gamma_{I}^{*}>0$ and their expected utility $v(1+\rho) \frac{\bar{\lambda}-\hat{\lambda}_{I}}{l}+\gamma_{I}^{*} v(1+\rho) \frac{\hat{\lambda}_{I}-\underline{\lambda}}{l}-\zeta$ is weakly positive. Both $\gamma_{I}^{*}$ and $\hat{\lambda}_{I}$ are as in section 3.1 .1 with $\alpha /(1+\rho)$ in place of $\alpha$, and thus $\gamma_{I}^{*}>\gamma^{*}$ and $\hat{\lambda}_{I}<\hat{\lambda}$. Hence, investment inducement weakly strengthens property rights protection. Since the original

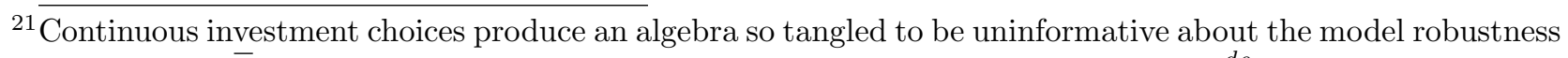
except in the $\bar{\lambda}$ large and $v$ small case when the basic analysis stands intact being $\frac{d \rho}{d \gamma^{*}}$ small. 
owners' expected payoff rises with $\gamma_{I}^{*}$, there is a $\tilde{\gamma}_{I}$ such that investment goes through only if optimal property rights are larger than $\tilde{\gamma}_{I}$. For $\gamma_{I}^{*}>\tilde{\gamma}_{I}$, society picks $\gamma_{I}^{*}$ instead of $\gamma^{*}$ if the social welfare is larger at $\gamma_{I}^{*}$ with investment than it is at $\gamma^{*}$ without. For $\gamma_{I}^{*} \leq \tilde{\gamma}_{I}$ instead, $\tilde{\gamma}_{I}$ is preferred to $\gamma^{*}$ if the social welfare is larger at $\tilde{\gamma}_{I}$ with investment than it is at $\gamma^{*}$ without. To elaborate, investment always goes through for $\alpha$ sufficiently small compared to $v$ and for $\rho(\zeta)$ not too small (large). For $v \geq \lambda_{m}$, then $\gamma^{*}=1$ and investment materializes.

In the case of transaction costs determined by the existence of market power, the fact that the original owners' expected utility is multiplied by $1+\rho$ implies that $\alpha_{I}^{*}=\alpha^{*}(1+\rho)$ and so $\gamma_{I}^{*}=\gamma^{*}$ and $\hat{\lambda}_{I}=\hat{\lambda}$. Since the original owners' expected payoff rises with $\gamma_{I}^{*}$, investment realizes only if $\gamma_{I}^{*}$ is larger than $\tilde{\gamma}_{I}$. As in the production case, $\tilde{\gamma}_{I}$ falls with $\alpha$ when the mark-up is sufficiently small compared to $v$. Under the same condition and for $\rho(\zeta)$ not too small (large), society picks the maximum $\hat{\gamma}_{I}$ between $\gamma_{I}^{*}$ and $\gamma_{I}$ since investment is socially beneficial. Finally, $\gamma_{I}^{*}=1$ and thus investment is always successful for $v \geq \lambda_{m}$.

For what concerns the scenario of transaction costs driven by lemon-type distortions, a glance at equation (4) suggests that society's objective function is now multiplied by $1+\rho$ and the analysis of the basic setup is unchanged provided that $\alpha<\frac{2}{1+\rho}$. High-valuation potential buyers buy for $\gamma^{*} \geq \frac{2}{\theta(1+\rho)}$ and expropriate otherwise. Once again, the original owners' expected utility rises with $\gamma_{I}^{*}$, and so investment prevails only if optimal property rights are larger than $\tilde{\gamma}_{I}$. Society then selects $\hat{\gamma}_{I}$ if investment is welfare enhancing and, in particular, if its fixed cost is sufficiently small and its return is sufficiently large.

\section{Evidence}

The main model implication is that incomplete property rights are efficient when transaction costs impede both trade and innovation whether or not constitution writers are benevolent and the disincentive to effort effect of weak property rights is taken into account. As a consequence, the main model testable prediction can be stated as follows:

Prediction: The strength of the original owners' (upstream firms') property rights falls with the severity of market frictions and failures (incomplete contracting costs), which rises with the dispersion in the traders' valuations (likelihood of a more productive technology).

The negative (positive) links between the measures of the protection of personal, in- 
tellectual, and financial property and the proxies for market frictions and failures (asset specificities) documented in section 2 are consistent with such a prediction. Yet, they may be capturing reverse causality, they may be driven by the confounding effect of omitted variables, or they may be attenuated by the error in the measurement of transaction costs.

\section{$4.1 \quad$ Identifying Causal Relationships}

I pursue several strategies to evaluate whether the correlations illustrated in section 2 are causal. First, I control for the other main drivers of property rights discussed by the extant literature. Second, I use selection on observables to assess the likelihood that the estimates are driven by unobservables. Finally, I devise a 2SLS approach based on the aforementioned positive dependence of market friction and failures (incomplete contracting costs) on the dispersion in the traders' valuations (likelihood of a more productive technology). ${ }^{22}$

\subsubsection{Controlling for Observables}

The key variables potentially omitted from the analysis of section 2 are those shaping property rights through channels other than the trade-off between inefficient exclusion from trade/innovation and expropriation and associated with transaction costs. They are the development level, the inclusiveness of political institutions, the level of state capacity, internal conflicts, and the extent of human capital accumulation. Next, I illustrate them in turn.

First, transaction costs could affect property rights through their adverse impact on economic development, which in turn is related to the protection of private rights through the modernization effect (Williamson, 2010). Accordingly, I consider the natural logarithm of the output-side real GDP at chained PPPs in 2011 US dollar per capita, i.e., Income.

Second, less inclusive political institutions obstruct the distribution of the rents from innovation and trade among non-elite (North, Wallis, and Weingast, 2009), while easing the expropriation of the property of private citizens by both politicians and elite members (Acemoglu and Johnson, 2005). To assess the importance of such a mechanism, I consider the constraints on the executive authority score from the POLITY IV dataset, i.e., Democracy. ${ }^{23}$

\footnotetext{
${ }^{22}$ For the data aggregated at the cross-sectional level moreover, I can confirm the core of the analysis and I cannot reject that transaction costs are exogenous and that the overidentifying restrictions hold.

${ }^{23}$ To illustrate, the score ranges between one and seven and assumes higher values when the holder of the executive power is accountable to the citizens and/or the government is constrained by checks and balances.
} 
Third, low levels of non-produced output worsening the disincentive to effort effect, the incidence of external wars, and German and Scandinavian legal origins are stable predictors of a state capacity to exchange/innovate and protect private rights (see Besley and Persson, [2009]; but also Guerriero, [2016b]). While I take into account the last factor through the country fixed effects, I assess the role of the first two by controlling for the crude oil proved reserves in barrels per capita - i.e., Reserves - and the share of previous half-century in which the country was involved in external military conflicts, i.e., Conflict-External.

Fourth, inter-groups conflicts are related to both large transaction costs (Seitz, Tarasov, and Zakharenko, 2015) and insecure private rights (Ashraf and Galor, 2013). I consider the role of these connections by incorporating into the analysis the share of previous half-century in which the country was involved in internal military conflicts, i.e., Conflict-Internal.

Fifth, more limited transaction costs provide incentives for investment in human capital (Foss, 2011), which in turn helps shift labor from traditional to modern sectors and so curb inequality and favor institutions that protect private property (Cervellati, Fortunato, and Sunde, 2008). To evaluate these patterns, I control for the ratio of the total tertiary enrollment regardless of age to the population of the relative age group, i.e., Human-Capital.

Finally, a culture of morality and the efficiency of public enforcement alter the incentives of intermediaries and thus the balance between protecting property and enhancing the reliance on contracts (Dari-Mattiacci and Guerriero, 2015). ${ }^{24}$ Moreover, they may shape the intensity of both exchange and innovation (Seitz, Tarasov, and Zakharenko, 2015). Estimates reported in the Internet appendix reveal that considering these factors greatly lowers the number of available observations but leaves essentially intact the gist of the analysis.

Including all these controls in the specification also factors in the heterogeneity in preference/productivity, which reduces the contribution to the social welfare of the utilities of those middle-valuation(productivity) potential buyers (downstream firms) whose exclusion from trade (innovation) is more socially costly (Guerriero, 2016a). Since transaction costs might be correlated with heterogeneity, this aspect of the identification strategy is key.

\footnotetext{
${ }^{24}$ While I proxy a culture of morality with the first principal component extracted from the level of generalized trust and the importance of respect self-reported to either the World Value Survey or the European Value Study, I measure the efficiency of public enforcement with the first principal component extracted from the number of police personnel and that of professional judges per 100,000 inhabitants as collected from the United Nations' surveys of crime trends and the operations of criminal justice systems.
} 
Panels (A) to (C) of table 4 report the estimates relative to the specifications with dependent variables Property-Rights, Intellectual-Property, and Shareholders-Protection respectively and considering all together the extra controls. The key observations are that the coefficients on these regressors are generally jointly insignificant, whereas those on the proxies for transaction costs are negative and significant at 5 percent or better and display a magnitude almost equal to their counterparts in table 3. In the same spirit, results available upon request reveal that the impacts of the proxies for transaction costs remain similar when considered together and that the extra controls contribute only marginally to the total $\mathrm{R}^{2} .{ }^{25}$

\subsubsection{Using Selection on Observables to Assess the Bias from Unobservables}

Despite my attempts to control for relevant observable factors, OLS estimates may still be biased by unobservables. To evaluate this issue, I calculate the index proposed by Altonji, Elder, and Taber (2005) to measure how much stronger selection on unobservables, relative to selection on observables, must be to explain away the full estimated effect. ${ }^{26}$ To see how the index is calculated, consider a regression with a restricted set of control variables and one with a full set of controls. Next, denote the estimate of the coefficient attached to a proxy for transaction costs from the first regression $\beta^{R}$, where $R$ stands for "restricted," and that from the second regression $\beta^{F}$, where $F$ stands for "full." Then, the index is the absolute value of $\beta^{F} /\left(\beta^{R}-\beta^{F}\right)$. The intuition behind the formula is as follows. The lower the absolute value of $\left(\beta^{R}-\beta^{F}\right)$ is, the less the estimate of the relevant coefficient is affected by selection on observables, and the stronger selection on unobservables needs to be to explain away the entire effect. Moreover, the higher the absolute value of $\beta^{F}$ is, the greater is the effect that needs to be explained away by selection on unobservables, and thus the higher is the index.

In table 5, I consider the specifications conditioning only for country and year fixed effects and reported in table 3 as the restricted regressions and those controlling for all observables in table 4 as the full regressions. The ratios calculated when the dependent variable is either Property-Rights, Intellectual-Property, or Shareholders-Protection are reported respectively in columns (1) to (3). None of them is less than one, and the median and average ratios

\footnotetext{
${ }^{25}$ According to the Shapley value decomposition, their contribution amounts on average only to the 13 percent, whereas the share explained by transaction costs (country and year fixed effects) is the 35 (52) percent.

${ }^{26}$ I use the version developed by Bellows and Miguel (2009) for possibly endogenous continuous variables.
} 
are 29.2 and 60. Therefore, to attribute the entire OLS estimates of the coefficients on the proxies for transaction costs to selection effects, selection on unobservables would have to be on average sixty times greater than selection on all observables, which seems unlikely.

\subsubsection{SLS Estimates: Property Rights and Endogenous Transaction Costs}

My final strategy is to use instrumental variables. This approach requires instruments that are correlated with transaction costs but uncorrelated with any other dimension affecting property rights. To achieve this goal, I build on the positive dependence of market failures (incomplete contracting costs) on the dispersion in the traders' valuations (likelihood of a more productive technology), and I use as excluded instruments for transaction costs two one to seven indexes. The first one captures the availability for firms of the latest technologies - i.e., Technology-Availability - and the other measures the quality of math and science education, i.e., Math-Science. This choice is consistent with Añón Higón et al. (2017), who build on over one million firm-level data for 23 EU states between 2003 and 2014 to document that more labor skilled firms are closer to the technology frontier and this pattern is more accentuated in service sectors. Such results have four crucial implications for my 2SLS estimation approach. First, countries endowed with a human capital more apt to absorb ideas and knowledge are those more likely to display not only smaller differences in firms' productivity but also a smaller dispersion in the payoffs of their users and thus a smaller extent of market power and more limited lemons-type distortions. Second, these are also the countries in which the likelihood of a more productive technology will be larger (Acemoglu, Aghion, and Zilibotti, 2006) and so will be the severity of asset specificities. Third, it reasonable to think that the very same drivers of market failures determine market frictions. Accordingly, Acemoglu, Aghion, and Zilibotti (2006) suggest that credit market imperfections are typical of countries further away from the technology frontier as opposed to those close to approach it. Finally, it seems unlikely that a society's inclination to spread and adopt more effectively innovation is systematically related to the protection of property rights conditional on the inclusiveness of political institutions, the level of state capacity, internal conflicts, fixed effects, and especially the level of development and human capital.

Table 6 reports in panels $(\mathrm{A})$ to $(\mathrm{C})$ the 2SLS estimates of the specifications with 
dependent variables respectively Property-Rights, Intellectual-Property, and ShareholdersProtection and controlling for all observables. Starting from the first stages, both TechnologyAvailability and Math-Science have always a negative (positive) and generally statistically significant relationship with the proxies for market friction and failures (incomplete contracting costs). Accordingly, I can always reject that the estimated equation is underidentified at 1 percent. Turning to the second stages, the proxies for market friction and failures (measure of incomplete contracting costs) have (has) always negative (positive) and strongly significant - at 1 percent - effects (impact) on the measures of property rights protection and the attached coefficients (coefficient) display(s) a magnitude very similar to those in table 4. Finally, I cannot reject that the overidentifying restrictions hold at a level nowhere lower than 5 percent and I document in the Internet appendix that the excluded instruments have no direct impact on property rights in the semi-reduced form regressions. Overall, these patterns support the inference made above and confirm the validity of the model prediction.

\section{Conclusions}

This paper has developed and tested a model clarifying how the protection of property rights is optimally weakened in the face of sizable costs of trading/innovating, and in particular market frictions and failures, and how these are more severe whenever the dispersion in the traders' valuations and the likelihood of a more productive technology are larger.

To characterize the general trade-off between inefficient exclusion from trade/innovation and expropriation guiding property rights selection, I study both the possibly consensual exchange of economic value between its original owner and a potential buyer and a downstream firm's choice of whether to produce in-house through an old technology or to adopt a new one necessitating an upstream firm's input. In the former case, fully protecting the original owners' property implies that some high-valuation potential buyers inefficiently refuse to buy it because of transaction costs. When instead property rights are weak, low-valuation potential buyers inefficiently expropriate the original owners' property. The trade-off between these two misallocations entails that the strength of property rights, and thus the size of

the market, will be more limited the larger transaction costs are regardless of whether they are driven by frictions outside the control of traders/innovators or determined by the mix of 
the dispersion in traders' valuations and either the original owners' market power or their privileged information. A similar conclusion holds true for the upstream firm's property rights on his input. Being the relative cost random and ex ante non contractible, a strong protection of the upstream firms' property discourages the downstream firms from innovating because of the risk of being held-up. When instead the upstream firms are only weakly protected, low-productivity downstream firms inefficiently exploit the input. Balancing these two misallocations entails that the protection of the upstream firms' property rights (size of the market) will be weaker (larger) the greater incomplete contracting costs are, i.e., the higher is the probability of low-cost realization. Crucially, these implications survive when a group of traders/innovators has a larger political influence on institutional design and when the disincentive to effort effect of weak property rights is taken into account.

To evaluate the central model predictions, I focus on a panel of 135 countries spanning the 2006-2015 period. OLS estimates suggest that the protection of the original owners' (downstream firms') property rights is the weakest (strongest) where market frictions-i.e., excessive regulation and financial inefficiencies - and failures - i.e., lack of the competitiveness of corporate activity and lemons-type distortions (incomplete contracting costs due to asset specificities) - are the largest. To determine if these relationships are indeed causal, I pursue three strategies. First, I control not only for country and year fixed effects, but also for the development level, the inclusiveness of political institutions, the strength of state capacity, internal conflicts, and the level of human capital. Considering these observables together leaves the results almost intact. Second, I calculate that the influence of unobservables would have to be on average sixty times greater than that of all observables to explain away the negative links between property rights and transaction costs. Finally, I use as excluded instruments proxies for both the availability of the latest technologies and the quality of math and science education. Conditional on all observables, the 2SLS estimates are strongly consistent with the OLS ones. In addition, the validity of the exclusion restriction is vindicated by the canonical under-identification and over-identification tests.

I close by highlighting how two central results of my analysis open key avenues for future research. First, the tendency of property rights toward optimality does not imply that the existing legal variation is irrelevant and thus does not warrant reforms. On the contrary, 
the model reveals that special interests can distort the design of property rights away from optimality when the political process is less than perfect. Second, weak property rights are society's response to the existence of sizable transaction costs, which in turn are driven by the dispersion in the traders' valuations and the likelihood of a more productive technology, and therefore their negative correlation with economic outcomes might be - at least partlyspurious. As a consequence, further research on the relationships among endogenous property rights, endogenous transaction costs, and economic outcomes is needed. 


\section{Appendix}

\section{Property Rights and Market Power}

The first-order condition of society's problem is $-\frac{\hat{\lambda}-\underline{\lambda}}{2 l}(\hat{\lambda}+\underline{\lambda}-2 v)=0$, whose left-hand side is the infra-marginal effect of a rise in $\gamma$. The latter can be negative only for $v<\lambda_{m}$.

\section{Property Rights and Lemons-type Distortions}

The high-valuation potential buyers' expected payoff from buying $\theta \frac{p_{L}}{2}-p_{L}$ is weakly greater than her expected payoff from expropriation $(1-\gamma) \theta \frac{p_{L}}{2}$ for $\gamma^{*}$ higher than $\frac{2}{\theta}<$ 1 being $\theta>2$. The middle(low)-valuation potential buyers instead do not buy because $\frac{\alpha p_{L}}{2}-p_{L}\left(\frac{p_{L}}{2 \theta}-p_{L}\right)<0$. For $\gamma^{*} \leq \frac{2}{\theta}$, the derivative of society's objective function with respect to $\gamma$ is $-\left[(1-\Delta)(\alpha-1)+\frac{(\theta-1)^{2}}{\theta} \frac{\Delta}{2}\right] \lambda_{m}$, which is negative. For $\gamma^{*}>\frac{2}{\theta}$ instead, it equals $-\left[(1-\Delta)(\alpha-1)-\frac{\theta-1}{\theta} \frac{\Delta}{2}\right] \lambda_{m}$, which falls with $\alpha$, rises with $\Delta$, is negative for $\Delta \rightarrow 0$, and positive for $\Delta \rightarrow 1$. $\gamma^{*}$ possibly jumps from 0 to 1 for $\alpha(\Delta)$ sufficiently small (large).

Considering a Generic Probability Density Function of the Potential Buyers' Valuation

In the case of exogenous transaction costs, potential buyers value $x$ at $\lambda \in[\underline{\lambda}, \bar{\lambda}]$ distributed according to the log-concave probability density function $f$ with cumulative distribution function $F$. Then, $\gamma^{*}$ maximizes $\int_{\hat{\lambda}}^{\bar{\lambda}}(\lambda-\alpha) d F(\lambda)+\int_{\underline{\lambda}}^{\hat{\lambda}}[(1-\gamma) \lambda+\gamma v] d F(\lambda)$ for $\hat{\lambda}<\bar{\lambda}$ and $W^{F E}$ otherwise. For $\hat{\lambda}<\bar{\lambda}, \gamma^{*}>0$ is defined by $\frac{1-\gamma^{*}}{\gamma^{*}} v \hat{\lambda} f(\hat{\lambda})-(\hat{\lambda}-v) F(\hat{\lambda})+$ $\int_{\underline{\lambda}}^{\hat{\lambda}} F(\lambda) d \lambda=0$ and society's objective function is sub-modular in $\gamma$ and $\alpha$ when $\frac{f^{\prime}(\hat{\lambda})}{f(\hat{\lambda})}<$ $\frac{\alpha}{v(v+\alpha)} \frac{\gamma^{*}}{1-\gamma^{*}}$. While the right-hand side of this inequality is greater than $\frac{\alpha}{v(\bar{\lambda}-v-\alpha)}$, its left-hand side is lower than $\frac{f^{\prime}}{f}(v+\alpha)$ since log-concavity of $f$ implies a decreasing $\frac{f^{\prime}}{f}$ (Dharmadhikari and Joag-Dev, 1988). Hence, the inequality is true and thus $\frac{d \gamma^{*}}{d \alpha} \leq 0$ for $\frac{f^{\prime}}{f}(v+\alpha)<\frac{\alpha}{v(\bar{\lambda}-v-\alpha)}$ or equally if $v$ is sufficiently large (see section 3.1 for the corresponding restriction in the basic setup). To understand this last remark, notice that the right-hand side of the sufficient condition increases with $v$ for $2 v>\bar{\lambda}-\alpha$, whereas its left-hand side is negative for $v+\alpha$ larger than the mode of $\lambda$, being every log-concave density function defined on a real support unimodal (Dharmadhikari and Joag-Dev, 1988). For $\hat{\lambda}<\bar{\lambda}$, the infra-marginal effect of a rise in $\gamma$ is $[v-E(\lambda \mid \lambda \leq \hat{\lambda})] F(\hat{\lambda})$, which can be negative only if $v<\lambda_{m}=E(\lambda) \geq E(\lambda \mid \lambda \leq \hat{\lambda})$. For $\hat{\lambda}<\bar{\lambda}$ and $v \geq \lambda_{m}$ therefore, $\gamma^{*}=1$. For $\hat{\lambda}<\bar{\lambda}$ and $v<\lambda_{m}$ instead, $\gamma^{*}$ can jump from 0 to the interior solution whenever $\int_{\hat{\lambda}}^{\bar{\lambda}}(\lambda-\alpha) d F(\lambda)+\int_{\underline{\lambda}}^{\hat{\lambda}}\left[\left(1-\gamma^{*}\right) \lambda+\gamma^{*} v\right] d F(\lambda)>\lambda_{m}$. 
This last condition is more difficult to satisfy the larger the transaction costs are since the derivative of its left-hand side with respect to $\alpha$ equals $-\frac{1-\gamma^{*}}{\gamma^{*}} v f(\hat{\lambda})-F(\bar{\lambda})+F(\hat{\lambda})<0$.

Next, I show that the results produced by the other setups survive to considering any $f$.

When the original owners have market power, two observations are key. First, the markup $\alpha^{*}$ maximizes now the original owners' expected payoff $\int_{\hat{\lambda}}^{\bar{\lambda}}(v+\alpha) d F(\lambda)+\int_{\underline{\lambda}}^{\hat{\lambda}} \gamma^{*} v d F(\lambda)$, whose derivative with respect to $\alpha$ is $1-F(\hat{\lambda})-(\hat{\lambda}-v) f(\hat{\lambda})$. Hence, $\frac{d \alpha^{*}}{d \gamma}=\hat{\lambda}$ and thus $\frac{d \hat{\lambda}}{d \gamma}=\left(\frac{d \alpha^{*}}{d \gamma} \gamma-v-\alpha^{*}\right) \frac{1}{\gamma^{2}}=0$. Again, the effect of a rise in the strength of optimal property rights on society's objective function $\int_{\hat{\lambda}}^{\bar{\lambda}} \lambda d F(\lambda)+\int_{\lambda}^{\hat{\lambda}}[(1-\gamma) \lambda+\gamma v] d F(\lambda)$ equals $-\frac{\hat{\lambda}-\underline{\lambda}}{2}(\hat{\lambda}+\underline{\lambda}-2 v) f(\hat{\lambda})$, which is negative for $\frac{v+\alpha^{*}}{\gamma^{*}}+\underline{\lambda}-2 v>0$ and positive otherwise. As in the baseline case of a uniform distribution $f, \gamma^{*}$ jumps from 0 to 1 as $\alpha^{*}$, which is either 0 or its maximum value $\bar{\alpha}=\min \{v, \bar{\lambda}-v\}$, becomes sufficiently small.

Turning to the scenario of transaction costs driven by lemon-type distortions, it follows from society's objective function that only the mean of the potential buyers' valuation distribution $\lambda_{m}$ matters. This remark highlights the full generality of the analysis.

For what finally concerns the case of transaction costs determined by incomplete contracting inefficiencies, society maximizes $\alpha \int_{\hat{\lambda}}^{\bar{\lambda}}(\lambda-v) d F(\lambda)+(1-\alpha) \int_{\hat{\lambda}}^{\bar{\lambda}}(\delta \lambda-v) d F(\lambda)+$ $\int_{\underline{\lambda}}^{\hat{\lambda}} \delta \lambda d F(\lambda)$, which strictly increases with $\gamma$ when $-\frac{d \hat{\lambda}}{d \gamma}[\alpha \hat{\lambda}+(1-\alpha) \delta \hat{\lambda}-v-\delta \hat{\lambda}] f(\hat{\lambda})=$ $-\frac{v^{2}(\alpha-1+\gamma)}{(1-\delta)(1-\gamma)^{3}} f(\hat{\lambda})>0$ or if $\gamma<1-\alpha$ and weakly decreases otherwise. Hence, the unique and global solution is $\gamma^{*}=1-\alpha$ as in the baseline scenario of a uniform distribution $f$.

\section{The Political Economy of Property Rights Protection}

In the case of exogenous transaction costs and excluded low-valuation potential buyers, the derivative of the objective function is $\frac{v^{2}-\alpha^{2}}{\left(\gamma^{*}\right)^{2}}+(\underline{\lambda}+\epsilon)^{2}-2 v \underline{\lambda}=0$ for $\hat{\lambda}<\bar{\lambda}$ and $v-\lambda_{m}+$ $\frac{2 \epsilon \lambda+\epsilon^{2}}{2 l}$ otherwise, the infra-marginal effect of a rise in $\gamma$ for $\hat{\lambda}<\bar{\lambda}$ is $-\frac{(\hat{\lambda}-\underline{\lambda}-\epsilon)(\hat{\lambda}+\underline{\lambda}+\epsilon-2 v)}{2 l}+\frac{2 v \epsilon}{2 l}$, and the second-order conditions are as in the basic setup. Thus, $\gamma^{*}$ is set inefficiently high, falls with $\alpha$ provided that $(\underline{\lambda}+\epsilon)^{2}-2 v \underline{\lambda}<0$ or $\epsilon$ not too large, and possibly jumps from 0 to the interior solution for $\alpha$ sufficiently small under the same condition discussed in the basic setup. When instead to be excluded are high-valuation potential buyers, society maximizes the objective function $\int_{\hat{\lambda}}^{\bar{\lambda}-\epsilon} \frac{\lambda-\alpha}{l} d \lambda+\int_{\underline{\lambda}}^{\hat{\lambda}} \frac{(1-\gamma) \lambda+\gamma v}{l} d \lambda$ for $\hat{\lambda}<\bar{\lambda}$ and $W^{F E}-(1-\gamma) \frac{2 \epsilon \bar{\lambda}-\epsilon^{2}}{2 l}$ otherwise. Both the infra-marginal effect of a rise in $\gamma$ and the first and second-order conditions for a positive solution are as in the baseline analysis, whereas for $\hat{\lambda} \geq \bar{\lambda}$ the first-order con- 
dition is $v-\lambda_{m}+\frac{2 \epsilon \bar{\lambda}-\epsilon^{2}}{2 l}$ and thus leads again to an inefficiently large $\gamma^{*}$. The condition such that $\gamma^{*}$ possibly jumps from 0 to the positive solution is easier to satisfy the smaller $\alpha$ is for $\alpha<\gamma^{*}(\bar{\lambda}-v-\epsilon)$ and thus under the basic model restrictions on $\alpha$ for $\epsilon$ small.

When original owners have market power, the only relevant case is $\lambda<\hat{\lambda}$ and society maximizes $\int_{\hat{\lambda}}^{\bar{\lambda}} \frac{\lambda}{l} d \lambda+\int_{\underline{\lambda}+\epsilon}^{\hat{\lambda}} \frac{(1-\gamma) \lambda+\gamma v}{l} d \lambda$, whose derivative with respect to $\gamma$ is $-\frac{(\hat{\lambda}-\underline{\lambda}-\epsilon)(\hat{\lambda}+\underline{\lambda}+\epsilon-2 v)}{2 l}+$ $\frac{2 v \epsilon}{2 l}$. Hence, equilibrium property rights jump from 0 to 1 for $\alpha^{*}$ and $\epsilon$ sufficiently small.

Turning to the case of transaction costs driven by lemon-type distortions and low(high)valuation potential buyers not participating in the institutional design, society's objective function is that of the basic setup with $(1-\gamma) \frac{\lambda_{m}}{\theta}\left(\frac{\Delta}{2}-\epsilon\right)$ in place of $(1-\gamma) \frac{\lambda_{m}}{\theta} \frac{\Delta}{2}$ $\left((1-\gamma) \theta \lambda_{m}\left(\frac{\Delta}{2}-\epsilon\right)\right.$ in place of $(1-\gamma) \theta \lambda_{m} \frac{\Delta}{2}$ for $\gamma^{*} \leq \frac{2}{\theta}$ and $\theta \lambda_{m}\left(\frac{\Delta}{2}-\epsilon\right)$ in place of $\theta \lambda_{m} \frac{\Delta}{2}$ otherwise). While for $\gamma^{*} \leq \frac{2}{\theta}$ the first-order condition of society's problem equals $-\left[(1-\Delta)(\alpha-1)+\frac{(\theta-1)^{2}}{\theta} \frac{\Delta}{2}-\frac{\epsilon}{\theta}\right] \lambda_{m}\left(-\left[(1-\Delta)(\alpha-1)+\frac{(\theta-1)^{2}}{\theta} \frac{\Delta}{2}-\epsilon \theta\right] \lambda_{m}\right)$ and so it is negative for $\epsilon$ not too large, for $\gamma^{*}>\frac{2}{\theta}$ it equals $-\left[(1-\Delta)(\alpha-1)-\frac{\theta-1}{\theta} \frac{\Delta}{2}-\frac{\epsilon}{\theta}\right] \lambda_{m}$ and thus is negative for $\Delta$ and $\epsilon$ small and $\alpha$ large (the baseline case analysis applies).

For what finally concerns the case of transaction costs determined by incomplete contracting inefficiencies, the equilibrium is the same whether or not a sufficiently small group of either high- or low- $\lambda$ downstream firms is kept out of the institutional design.

Crucially, the political economy case can be generalized to the consideration of generic distributions of $\lambda$ and/or the inclusion of production and investment activities.

\section{Production}

In the case of exogenous transaction costs, the original owners' expected utility equals $\frac{v(\bar{\lambda}-\hat{\lambda})}{l}+\frac{\gamma^{*} v(\hat{\lambda}-\underline{\lambda})}{l}-\kappa$ and thus $\tilde{\gamma}$ is implicitly defined by $\frac{v\left[\bar{\lambda}-(v+\alpha) \tilde{\gamma}^{-1}\right]}{l}+\frac{\tilde{\gamma} v\left[(v+\alpha) \tilde{\gamma}^{-1}-\underline{\lambda}\right]}{l}=\kappa$, whose left-hand side rises with $\tilde{\gamma}$ because $-\frac{d \hat{\lambda}}{d \tilde{\gamma}} \frac{v}{l}(1-\tilde{\gamma})+\frac{v(\hat{\lambda}-\underline{\lambda})}{l}=\frac{v \hat{\lambda}}{\tilde{\gamma} l}(1-\tilde{\gamma})+\frac{v(\hat{\lambda}-\underline{\lambda})}{l} \geq$ 0 . Thus, production realizes for $\gamma^{*} \geq \tilde{\gamma}$. When the original owners have market power, their expected utility is $\frac{\left(v+\alpha^{*}\right)(\bar{\lambda}-\hat{\lambda})}{l}+\frac{\gamma^{*} v(\hat{\lambda}-\underline{\lambda})}{l}-\kappa$, and $\tilde{\gamma}$ is defined by $\frac{\left(v+\alpha^{*}\right)\left[\bar{\lambda}-\left(v+\alpha^{*}\right) \tilde{\gamma}^{-1}\right]}{l}+$ $\frac{\tilde{\gamma} v\left[\left(v+\alpha^{*}\right) \tilde{\gamma}^{-1}-\underline{\lambda}\right]}{l}=\kappa$, whose left-hand side rises with $\tilde{\gamma}$ because $-\frac{d \hat{\lambda}}{d \tilde{\gamma}} \frac{v(1-\tilde{\gamma})+\alpha^{*}}{l}+\frac{v(\hat{\lambda}-\underline{\lambda})}{l}=$ $\frac{\hat{\lambda}}{\tilde{\gamma} l}\left[v(1-\tilde{\gamma})+\alpha^{*}\right]+\frac{v(\hat{\lambda}-\underline{\lambda})}{l} \geq 0$ and rises with $\alpha$ if $-\frac{d \hat{\lambda}}{d \alpha} \frac{v(1-\tilde{\gamma})+\alpha^{*}}{l}+\frac{\bar{\lambda}-\hat{\lambda}}{l}=-\frac{v(1-\tilde{\gamma})+\alpha^{*}}{\tilde{\gamma} l}+\frac{\bar{\lambda}-\hat{\lambda}}{l} \geq 0$ or for $\bar{\lambda}$ large and $v$ not too small compared to $\alpha^{*}$ and so $\gamma^{*} \rightarrow 1$. Hence, production realizes for $\gamma^{*} \geq \tilde{\gamma}$, and $\frac{d \tilde{\gamma}}{d \alpha} \leq 0$. For what finally concerns the scenario of transaction costs driven by lemon-type distortions, the original owners' expected utility is $\frac{\Delta}{2} p_{L}+\left(1-\frac{\Delta}{2}\right) \gamma^{*} \lambda_{m}-\kappa$ 
and $\tilde{\gamma}$ is independent of $\alpha$ being equal to $\frac{2 \kappa-\Delta p_{L}}{(2-\Delta) \lambda_{m}}$. Once again, $x$ is produced if $\gamma^{*} \geq \tilde{\gamma}$.

\section{Investment}

With exogenous transaction costs, potential buyers buy if $\lambda(1+\rho)-v(1+\rho)-\alpha \geq$ $\left(1-\gamma_{I}\right) \lambda$ or $\lambda \geq \hat{\lambda}_{I} \equiv \frac{v+\alpha(1+\rho)^{-1}}{\gamma_{I}}$ and thus society's objective function is $\int_{\hat{\lambda}_{I}}^{\bar{\lambda}} \frac{\lambda(1+\rho)-\alpha}{l} d \lambda+$ $(1+\rho) \int_{\underline{\lambda}}^{\hat{\lambda}_{I}} \frac{(1-\gamma) \lambda+\gamma v}{l} d \lambda, \gamma_{I}^{*}=\frac{v^{2}-\left(\frac{\alpha}{1+\rho}\right)^{2}}{\underline{\lambda}(2 v-\underline{\lambda})}$, and the original owners' expected payoff from investment equals $v(1+\rho) \frac{\left(\bar{\lambda}-\hat{\lambda}_{I}\right)}{l}+\gamma_{I}^{*} v(1+\rho) \frac{\hat{\lambda}_{I}-\underline{\lambda}}{l}-\zeta$, whose derivative with respect to $\gamma_{I}^{*}$ is $-\frac{d \hat{\lambda}_{I}}{d \gamma_{I}^{*}} v(1+\rho) \frac{\left(1-\gamma_{I}^{*}\right)}{l}+v(1+\rho) \frac{\hat{\lambda}_{I}-\underline{\lambda}}{l} \geq 0$. For $\gamma_{I}^{*}>\tilde{\gamma}_{I}$, society picks $\gamma_{I}^{*}$ if the social welfare is larger at $\gamma_{I}^{*}$ with investment than it is at $\gamma^{*}$ without or whenever the inequality $\int_{\hat{\lambda}_{I}}^{\bar{\lambda}} \frac{\lambda(1+\rho)-\alpha}{l} d \lambda-\int_{\hat{\lambda}}^{\bar{\lambda}} \frac{\lambda-\alpha}{l} d \lambda+(1+\rho) \int_{\underline{\lambda}}^{\hat{\lambda}_{I}} \frac{\left(1-\gamma_{I}^{*}\right) \lambda+\gamma_{I}^{*} v}{l} d \lambda-\int_{\underline{\lambda}}^{\hat{\lambda}} \frac{\left(1-\gamma^{*}\right) \lambda+\gamma^{*} v}{l} d \lambda-\zeta \geq 0$ holds. The left hand side of this condition is larger than $(1+\rho)\left(\gamma^{*} \hat{\lambda}^{2}-\gamma_{I}^{*} \hat{\lambda}_{I}^{2}\right)+\left(\gamma_{I}^{*}-\gamma^{*}\right) \underline{\lambda}^{2}(1+\rho)+$ $2 v\left[(1+\rho) \gamma_{I}^{*}\left(\hat{\lambda}_{I}-\underline{\lambda}\right)-\gamma^{*}(\hat{\lambda}-\underline{\lambda})\right]-2 \alpha\left(\hat{\lambda}-\hat{\lambda}_{I}\right)-\zeta l$, which is positive for $\alpha$ sufficiently small compared to $v$ and so $\gamma_{I}^{*} \rightarrow \gamma^{*}$ and for $\rho(\zeta)$ not too small (large). A similar analysis applies to the $\gamma_{I}^{*} \leq \tilde{\gamma}_{I}$ scenario when society chooses $\tilde{\gamma}_{I}$ and not $\gamma^{*}$ if the social welfare is larger at $\tilde{\gamma}_{I}$ with investment than it is at $\gamma^{*}$ without investment. In the former case, $\hat{\lambda}_{I}$ is evaluated at $\tilde{\gamma}_{I}$. If $v \geq \lambda_{m}$ finally, then $\gamma^{*}=1$ and investment is certain.

When the original owners have market power, their expected utility rises with and falls with $\alpha$ if $-\frac{d \hat{\lambda}}{d \alpha} \frac{v\left(1-\tilde{\gamma}_{I}\right)(1+\rho)+\alpha^{*}}{l}+\frac{\bar{\lambda}-\hat{\lambda}}{l}=-\frac{v\left(1-\tilde{\gamma}_{I}\right)+\alpha^{*}}{\tilde{\gamma}_{I}(1+\rho) l}+\frac{\bar{\lambda}-\hat{\lambda}}{l} \geq 0$ or if $v$ is not too small compared to $\alpha^{*}$ since then $\gamma^{*} \rightarrow 1$. Hence, $\tilde{\gamma}_{I}$ falls with $\alpha$ when the mark-up is sufficiently small compared to $v$ and society selects $\hat{\gamma}_{I}$ if investment is welfare enhancing. For $\gamma^{*}>\tilde{\gamma}_{I}$, this is the case if $\rho \int_{\hat{\lambda}}^{\bar{\lambda}} \frac{\lambda}{l} d \lambda+\rho \int_{\underline{\lambda}}^{\hat{\lambda}} \frac{\left(1-\gamma^{*}\right) \lambda+\gamma^{*} v}{l} d \lambda-\zeta \geq 0$ and therefore for $\rho(\zeta)$ not too small (large). For $\gamma^{*} \leq \tilde{\gamma}_{I}$ instead, the analysis is as in the exogenous transaction costs case and $\tilde{\gamma}_{I}$ is selected for $\alpha$ small compared to $v$ and so $\gamma_{I}^{*} \rightarrow \gamma^{*}$ and for $\rho(\zeta)$ not too small (large).

For what finally concerns the scenario of transaction costs driven by lemon-type distortions, the original owners' expected utility is $\frac{\Delta}{2} p_{L}(1+\rho)+\left(1-\frac{\Delta}{2}\right) \gamma^{*} \lambda_{m}(1+\rho)-\kappa$, and $\tilde{\gamma}_{I}=\frac{2 \kappa-\Delta p_{L}(1+\rho)}{(2-\Delta) \lambda_{m}(1+\rho)}$, and $\gamma_{I}^{*}$ is as in the basic setup. Investment prevails only if optimal property rights are larger than $\tilde{\gamma}_{I}$, and society then selects $\hat{\gamma}_{I}$ if investment is welfare enhancing. For $\gamma^{*}>\tilde{\gamma}_{I}$, this is the case if $\theta \lambda_{m} \frac{\Delta}{2}+(1-\Delta)\left[\left(1-\gamma^{*}\right) \alpha \lambda_{m}+\gamma^{*} \lambda_{m}\right]+\left[\left(1-\gamma^{*}\right) \frac{\lambda_{m}}{\theta}+\gamma^{*} \lambda_{m}\right] \frac{\Delta}{2} \geq$ $\zeta \rho^{-1}$ and so for $\rho(\zeta)$ not too small (large). For $\gamma^{*} \leq \tilde{\gamma}_{I}$ instead, society selects $\tilde{\gamma}_{I}$ if $\rho \theta \lambda_{m} \frac{\Delta}{2}+\left[(1+\rho)\left(1-\tilde{\gamma}_{I}\right)-\left(1-\gamma^{*}\right)\right]\left[(1-\Delta) \alpha \lambda_{m}+\frac{\lambda_{m}}{\theta} \frac{\Delta}{2}\right]+\left(1-\frac{\Delta}{2}\right)\left(\tilde{\gamma}_{I}-\gamma^{*}\right) \lambda_{m}-\zeta \geq 0$ and so for $\alpha$ small relative to $v$ and so $\gamma_{I}^{*} \rightarrow \gamma^{*}$ and for $\rho(\zeta)$ not too small (large). 


\section{References}

Acemoglu, Daron, and Simon Johnson. 2005. "Unbundling Institutions." Journal of Political Economy, 113: 949-995.

Acemoglu, Daron, Philippe Aghion, and Fabrizio Zilibotti. 2006. "Distance to Frontier, Selection, and Economic Growth." Journal of the European Economic Association, 4: $37-74$.

Aghion, Philippe, Yann Algan, Pierre Cahuc, and Andrei Shleifer. 2010. "Regulation and Distrust." Quarterly Journal of Economics, 125: 1015-1049.

Allen, Douglas W. 2000. "Transaction Costs." In Encyclopedia of Law and Economics, Vol. I. Boudewijn Bouckaert and Gerrit De Geest, eds. Chelthenham: Edward Elgar Press: 893-926.

Altonji, Joseph G., Todd E. Elder, and Christopher R. Taber. 2005. "Selection on Observed and Unobserved Variables: Assessing the Effectiveness of Catholic Schools." Journal of Political Economy, 113: 151-184.

Añón Higón, M. Dolores, Juan A. Máñez, María E. Rochina-Barrachina, Amparo Sanchis, and Juan A. Sanchis. 2017. "The Determinants of the Distance to TFP Frontier among European Firms." Unpublished.

Arruñada, Benito, Giorgio Zanarone, and Nuno Garoupa. 2017. "Property Rights in Sequential Exchange." Unpublished.

Ashraf, Quamrul, and Oded Galor. 2013. "Genetic Diversity and the Origins of Cultural Fragmentation." American Economic Review, 103: 528-533.

Bar-Gill, Oren, and Nicola Persico. 2016. "Exchange Efficiency with Weak Ownership Rights." American Economic Journal: Microeconomics, 8: 230-267.

Barry, Jordan M., John William Hatfield, and Scott Duke Kominers. 2014. "Coasean KeepAway: Voluntary Transaction Costs." Unpublished. 
Barzel, Yoram. 1989. Economic Analysis of Property Rights. Cambridge University Press.

Bellows, John, and Edward Miguel. 2009. "War and Local Collective Action in Sierra Leone." Journal of Public Economics, 93: 1144-1157.

Besley, Timothy, and Maitreesh Ghatak. 2010. "Property Rights and Economic Development." In Handbook of Development Economics, Vol. V. Mark Rosenzweig and Dani Rodrik, eds. Amsterdam: Elsevier: 4525-4595.

Besley, Timothy, and Torsten Persson. 2009. "The Origins of State Capacity: Property Rights, Taxation and Politics." American Economic Review, 99: 1218-1244.

Bond, Eric W., and Kamal Saggi. 2017. "Compulsory Licensing and Patent Protection: a North-South Perspective." Forthcoming at the Economic Journal.

Bouckeart, Boudewijn, and Gerrit De Geest. 1995. "Private Takings, Private Taxes and Private Compulsory Services: The Economic Doctrine of Quasi Contracts." International Review of Law and Economics, 15: 463-487.

Brueckner, Jan K., and Harris Selod. 2009. "A Theory of Urban Squatting and Land-Tenure Formalization in Developing Countries." American Economic Journal: Economic Policy, 1: $28-51$.

Burk, Dan L., and Brett McDonnel. 2007. "The Goldilocks Hypothesis: Balancing Intellectual Property Rights at the Boundary of the Firm." University of Illinois Law Review, 2: $575-636$.

Calabresi, Guido, and Douglas A. Melamed. 1972. "Property Rules, Liability Rules and Inalienability: One View of the Cathedral." Harvard Law Review, 85: 1089-1128.

Cervellati, Matteo, Piergiuseppe Fortunato, and Uwe Sunde. 2008. "Hobbes to Rousseau: Inequality, Institutions, and Development." Economic Journal, 118: 1354-1384.

Charnoz, Olivier, and Ashwini Swain. 2012. "In Pursuit of Energy Efficiency in India's Agriculture: Fighting "Free Power" or Working with it?" Unpublished. 
Cook, R. Dennis. 1977. "Detection of Influential Observations in Linear Regression." Technometrics, 19: 15-18.

Croutzet, Alexandre, and Pierre Lasserre. 2017. "Optimal Completeness of Property Rights on Renewable Resources in the Presence of Market Power." Resource and Energy Economics, 49: 16-32.

Dari-Mattiacci, Giuseppe. 2012. "Endogenous Transaction Costs." Unpublished.

Dari-Mattiacci, Giuseppe, and Carmine Guerriero. 2015. "Law and Culture: A Theory of Comparative Variation in Bona Fide Purchase Rules." Oxford Journal of Legal Studies, 35: $543-574$.

Dharmadhikari, Sudhakar, and Kumar Joag-Dev. 1988. Unimodality, Convexity, and Applications. Boston, MA: Academic Press.

Felli, Leonardo, and Antonio Merlo. 2006. "Endogenous Lobbying." Journal of the European Economic Association, 4: 180-215.

Foss, Nicolai J. 2011. "Human Capital and Transaction Cost Economics." In the Oxford Handbook of Human Capital, Alan BurtonJones and J.C. Spender, eds. Oxford: Oxford University Press: 165-185.

Ganglmair, Bernhard. 2017. "Efficient Material Breach of Contract." Forthcoming at the Journal of Law, Economics, and Organization.

Gennaioli, Nicola. 2013. "Optimal Contracts with Enforcement Risk." Journal of the European Economic Association, 11: 59-62.

Ghosh, Shubha. 2014. "The Implementation of Exhaustion Policies: Lessons from National Experiences." Unpublished.

Grossman, Sanford J., and Oliver D. Hart. 1986. "The Costs and Benefits of Ownership: A Theory of Vertical and Lateral Integration." Journal of Political Economy, 94: 691-719. 
Guerriero, Carmine. 2016a. "Endogenous Property Rights." Journal of Law and Economics, 59: 313-358.

Guerriero, Carmine. 2016b. "Endogenous Legal Traditions and Economic Outcomes." Journal of Comparative Economics, 44: 416-433

Guerriero, Carmine. 2017. "Endogenous Property Rights and the Nature of the Firm." Unpublished.

Hart, Oliver, and John Moore. 1990. "Property Rights and the Nature of the Firm." Journal of Political Economy, 98: 1119-1158.

Hasen, Richard L., and Richard H. McAdams. 1997. "The Surprisingly Complex Case Against Theft." International Review of Law and Economics, 17: 367-378.

Johnson, Simon, Rafael La Porta, Florencio Lopez-de-Silanes, and Andrei Shleifer. 2000. "Tunneling." American Economic Review, 90: 22-27.

Jordan, Jim. 2006. "Pillage and Property." Journal of Economic Theory, 131: 26-44.

North, Douglass C., John J. Wallis, Barry R. Weingast. 2009. Violence and Social Orders: A Conceptual Framework for Interpreting Recorded Human History. Cambridge, UK: Cambridge University Press.

Piazzesi, Monika, Martin Schneider, and Johannes Stroebel. 2017. "Segmented Housing Search." Unpublished.

Sackman, Julius, at al. 2013. Nichols on Eminent Domain. Albany, New York, NY: Matthew Bender.

Segal, Ilya, and Michael Whinston. 2016. "Property Rights and the Efficiency of Bargaining." Journal of the European Economic Association, 14: 1287-1328.

Seitz, Michael, Alexander Tarasov, Roman Zakharenko. 2015. "Trade Costs, Conflicts, and Defense Spending." Journal of International Economics, 95: 305-318. 
Smith, Adam. 2017. "An Inquiry into the Nature and Causes of the Wealth of Nations." Oxford: Oxford University Press.

Williamson, Oliver E. 2010. "Transaction Cost Economics: The Natural Progression." American Economic Review, 100: 673-690.

World Economic Forum-WEF. 2015. "The Global Competitiveness Report 2014-2015." Geneva: WEF Press.

\title{
Tables and Figures
}

Table 1: Full Sample

\begin{abstract}
Albania; Algeria; Angola; Argentina; Armenia; Australia; Austria; Azerbaijan; Bahrain; Bangladesh; Belgium; Benin; Bhutan; Bolivia; Croatia; Cyprus; Czech Republic; Denmark; Dominican Republic; Ecuador; Egypt; El Salvador; Estonia; Ethiopia; Finland; France; Gabon; Gambia; Germany; Ghana; Greece; Guatemala; Guinea; Honduras: Hungary; India; Indonesia; Iran; Ireland; Israel; Italy; Jamaica; Japan; Jordan; Kazakhstan; Kenya; Kuwait; Kyrgyz Republic; Lao; Latvia; Lebanon; Lesotho; Liberia; Lithuania; Luxembourg; Macedonia; Madagascar; Malawi; Malaysia; Mali; Mauritania; Mauritius; Mexico; Moldova; Mongolia; Montenegro; Morocco; Mozambique; Myanmar; Namibia; Nepal; Netherlands; New Zealand; Nicaragua; Nigeria; Norway; Oman; Pakistan; Panama; Paraguay; Peru; Philippines; Poland; Portugal; Qatar; Romania; Russia; Rwanda; Saudi Arabia; Senegal; Serbia; Sierra Leone; Singapore; Slovak Republic; Slovenia; South Africa; Spain; Sri Lanka; Suriname; Swaziland; Sweden; Switzerland; Syria; Taiwan; Tajikistan; Tanzania; Thailand; Trinidad \& Tobago; Tunisia; Turkey; Uganda; Ukraine; United Arab Emirates; United Kingdom; United States; Uruguay; Venezuela; Vietnam; Yemen; Zambia; Zimbabwe.
\end{abstract}

Table 2: Summary of Variables

\begin{tabular}{|c|c|c|c|}
\hline & Variable & Definition and Sources & Statistics \\
\hline \multirow{3}{*}{$\begin{array}{l}\text { Property } \\
\text { rights: }\end{array}$} & Property-Rights: & $\begin{array}{l}\text { Index ranging between one and seven and gaging the strength of generic property } \\
\text { rights. Source: } 2006-2015 \text { EOS, available at https://www.weforum.org/reports/ }\end{array}$ & $\begin{array}{c}4.388 \\
(1.034)\end{array}$ \\
\hline & Intellectual-Property: & $\begin{array}{l}\text { Index ranging between one and seven and gaging how strong are intellectual } \\
\text { property rights. Source: } 2006-2015 \text { EOS. }\end{array}$ & $\begin{array}{c}3.713 \\
(1.124)\end{array}$ \\
\hline & Shareholders-Protection: & $\begin{array}{l}\text { Index ranging between one and seven and gaging to what extent are the interests } \\
\text { of minority shareholders protected by the legal system. Source: } 2006-2015 \text { EOS. }\end{array}$ & $\begin{array}{c}4.305 \\
(0.750)\end{array}$ \\
\hline \multirow{6}{*}{$\begin{array}{l}\text { Transaction } \\
\text { costs: }\end{array}$} & Over-Regulation: & $\begin{array}{l}\text { Index ranging between one and seven and gaging how burdensome is for firms to } \\
\text { comply with governmental administrative requirements. Source: } 2006-2015 \text { EOS. }\end{array}$ & $\begin{array}{c}3.708 \\
(0.658)\end{array}$ \\
\hline & Unavailability-Financing: & $\begin{array}{l}\text { Index ranging between one and seven and gaging the financial sector difficulties } \\
\text { in providing products and services to businesses. Source: } 2006-2015 \text { EOS. }\end{array}$ & $\begin{array}{l}2.489 \\
(0.955)\end{array}$ \\
\hline & Market-Dominance: & $\begin{array}{l}\text { Index ranging between one and seven and falling with the competitiveness of } \\
\text { corporate activity. Source: } 2006-2015 \text { EOS. }\end{array}$ & $\begin{array}{c}3.168 \\
(0.837)\end{array}$ \\
\hline & Trade-Barriers: & $\begin{array}{l}\text { Index ranging between one and seven and gaging how much non-tariff barriers curb } \\
\text { imported goods ability to compete with domestic ones. Source: 2006-2015 EOS. }\end{array}$ & $\begin{array}{l}2.545 \\
(0.685)\end{array}$ \\
\hline & Asymmetric-Information: & $\begin{array}{l}\text { Index ranging between one and seven and falling with the extent of information used } \\
\text { by buyers to make purchasing decisions. Source: 2006-2015 EOS. }\end{array}$ & $\begin{array}{l}3.447 \\
(0.835)\end{array}$ \\
\hline & Asset-Specificities: & $\begin{array}{l}\text { Index ranging between one and seven and gaging the competitive advantage of the } \\
\text { country's companies in international markets. Source: 2006-2015 EOS. }\end{array}$ & $\begin{array}{c}3.595 \\
(1.015)\end{array}$ \\
\hline \multirow{6}{*}{$\begin{array}{l}\text { Other } \\
\text { controls: }\end{array}$} & Income: & $\begin{array}{l}\text { Natural logarithm of the output-side real GDP at chained PPPs in } 2011 \text { US dollar } \\
\text { per capita. Source: Penn World Table 9.0, available at https://pwt.sas.upenn.edu/ }\end{array}$ & $\begin{array}{c}9.213 \\
(1.194)\end{array}$ \\
\hline & Democracy: & $\begin{array}{l}\text { Polity IV constraints on the executive authority score ranging between one and } \\
\text { seven. Source: POLITY IV dataset, available at http://www.systemicpeace.org }\end{array}$ & $\begin{array}{c}5.303 \\
(1.875)\end{array}$ \\
\hline & Reserves: & $\begin{array}{l}\text { Crude oil proved reserves in barrels per capita. Source: Energy Information } \\
\text { Administration, available at http://www.eia.gov/ }\end{array}$ & $\begin{array}{l}1895.327 \\
(9400.035)\end{array}$ \\
\hline & Conflict-External: & $\begin{array}{l}\text { Share of previous half-century in which the country was involved in external } \\
\text { military conflicts. Source: http://www.correlatesofwar.org/ }\end{array}$ & $\begin{array}{c}0.014 \\
(0.050)\end{array}$ \\
\hline & Conflict-Internal: & $\begin{array}{l}\text { Share of previous half-century in which the country was involved in internal } \\
\text { military conflicts. Source: http://www.correlatesofwar.org/ }\end{array}$ & $\begin{array}{c}0.064 \\
(0.120)\end{array}$ \\
\hline & Human-Capital: & $\begin{array}{l}\text { Ratio of total tertiary enrollment, regardless of age, to the population of the relative } \\
\text { age group. Source: 2006-2015 EOS. }\end{array}$ & $\begin{array}{l}33.758 \\
(25.843)\end{array}$ \\
\hline \multirow{2}{*}{$\begin{array}{l}\text { Excluded } \\
\text { instruments: }\end{array}$} & Technology-Availability: & $\begin{array}{l}\text { Index ranging between one and seven and gaging the availability of the latest } \\
\text { technologies. Source: } 2006-2015 \text { EOS. }\end{array}$ & $\begin{array}{c}4.634 \\
(1.033)\end{array}$ \\
\hline & Math-Science: & $\begin{array}{l}\text { Index ranging between one and seven and gaging the quality of math and science } \\
\text { education. Source: } 2006-2015 \text { EOS. }\end{array}$ & $\begin{array}{c}3.943 \\
(0.975)\end{array}$ \\
\hline
\end{tabular}


Figure 1: Strength of Property Rights Protection

Property-Rights
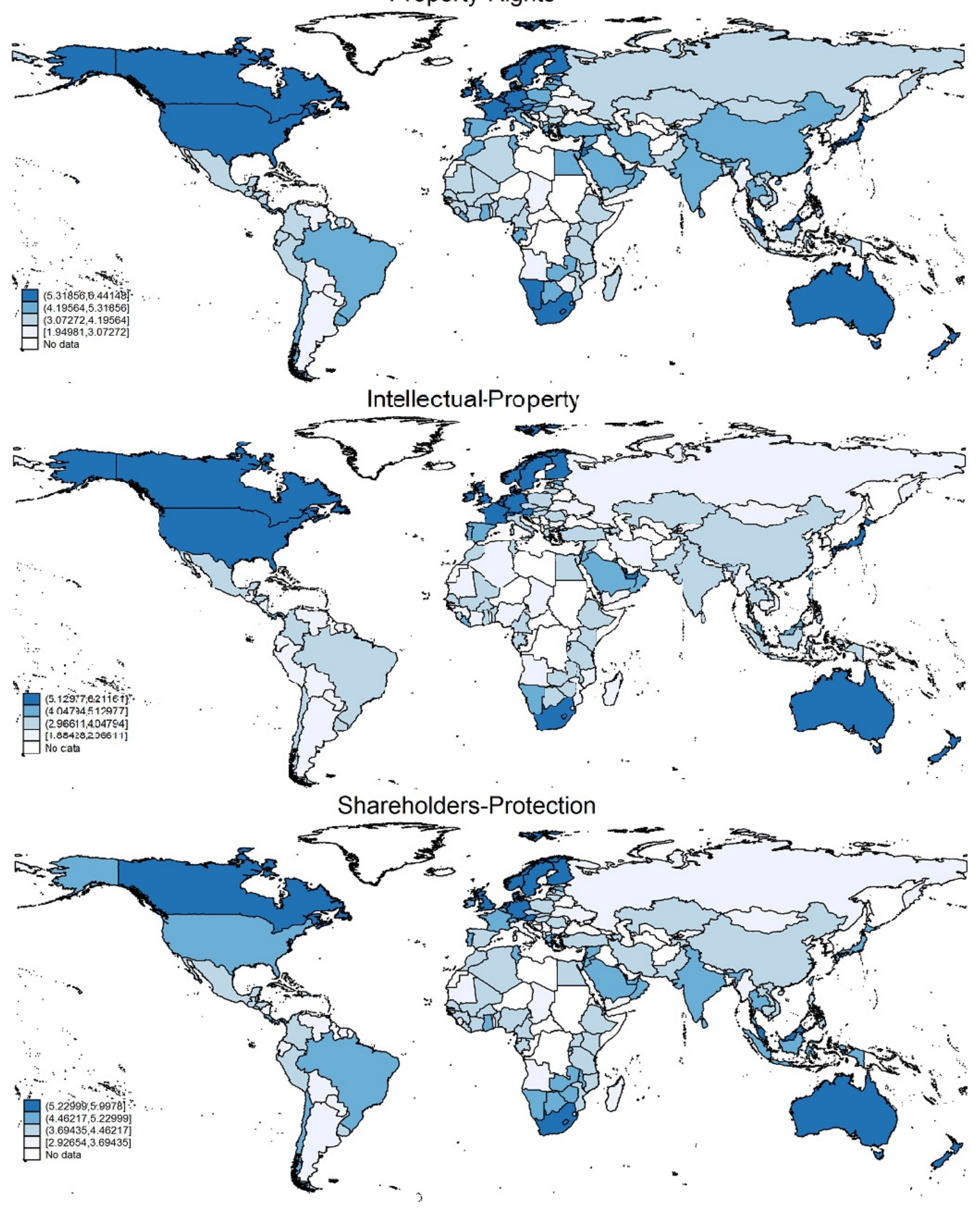

Note: 1. Here, I divide the range of each of the four variables, whose definitions and sources are listed in table 2 , into four equal intervals. 
Figure 2: Property Rights and Financial Inefficiencies

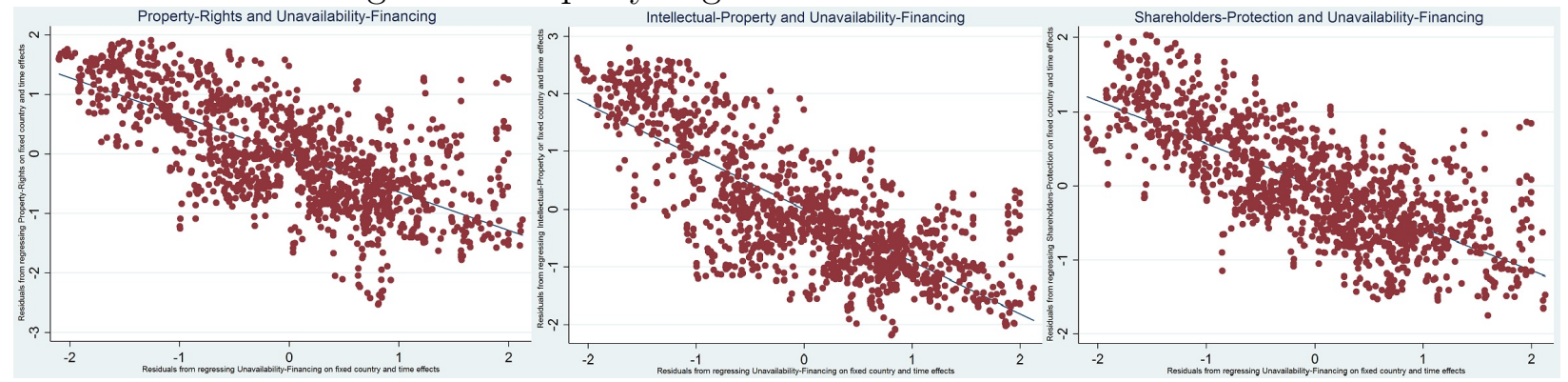

Note: 1. Residuals and fitted values lines are obtained from the sample employed in table 3.

Figure 3: Property Rights and Market Power

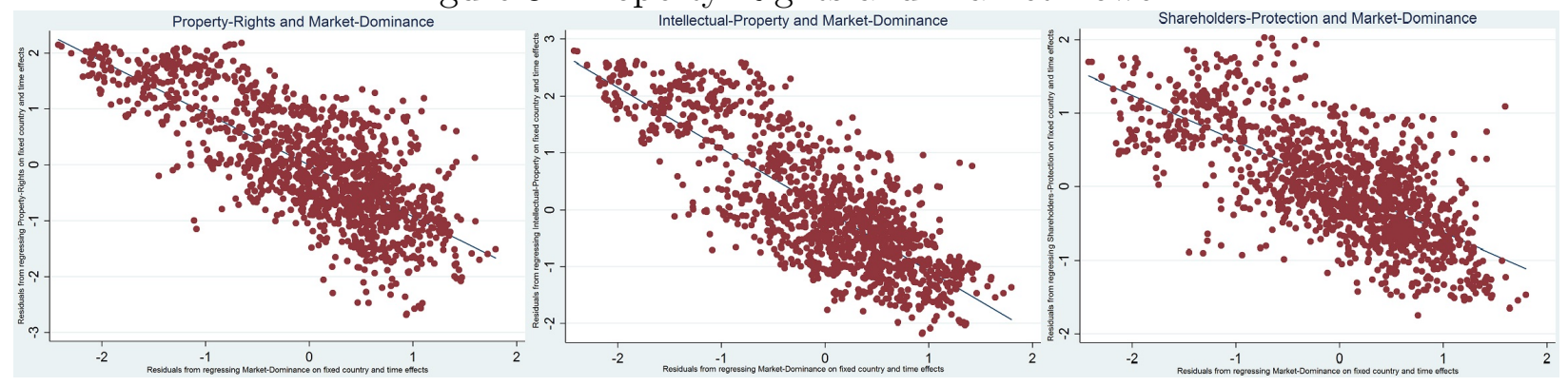

Note: 1. Residuals and fitted values lines are obtained from the sample employed in table 3

Figure 4: Property Rights and Lemons-type Distortions

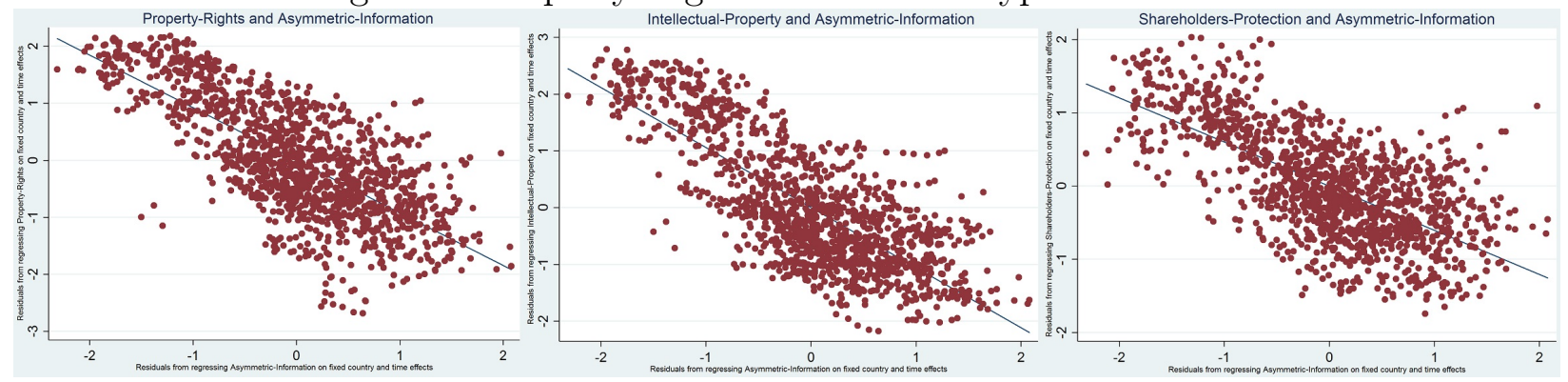

Note: $1 . \quad$ Residuals and fitted values lines are obtained from the sample employed in table 3. 
Figure 5: Downstream Firm's Property Rights and Incomplete Contracting Costs
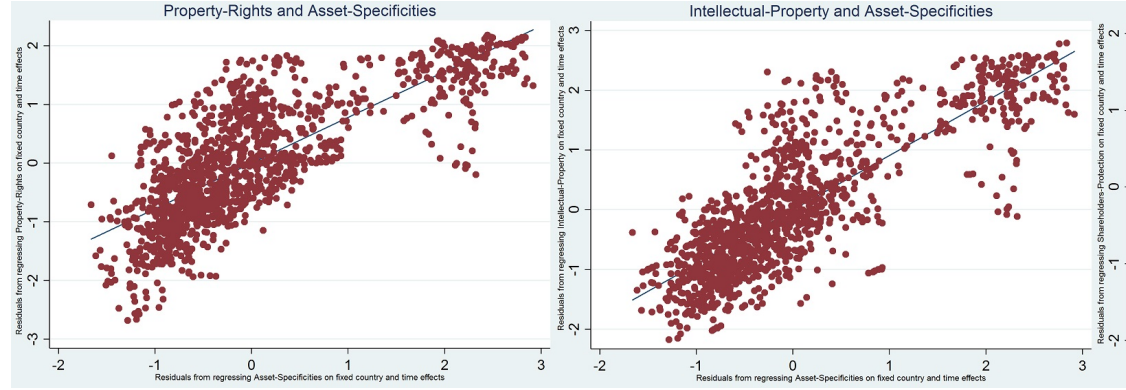
Shareholders-Protection and Asset-Specificities

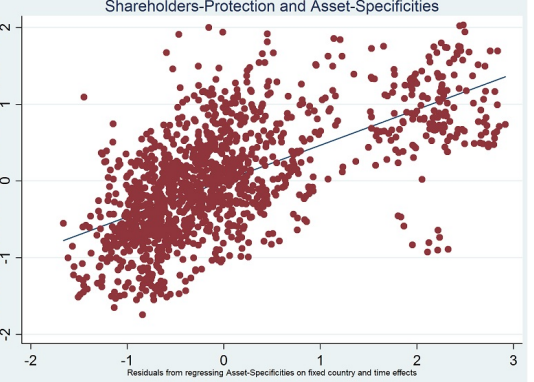

Note: 1. Residuals and fitted values lines are obtained from the sample employed in table 3.

Figure 6: Property Rights and Transaction Costs

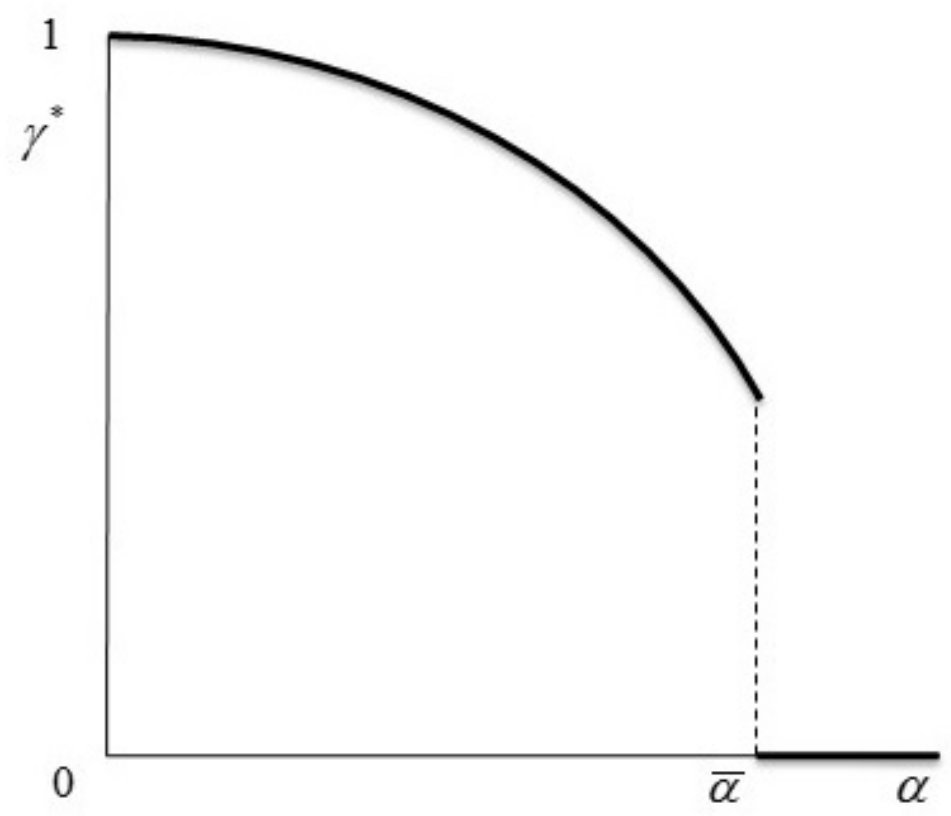


Table 3: Property Rights and Transaction Costs

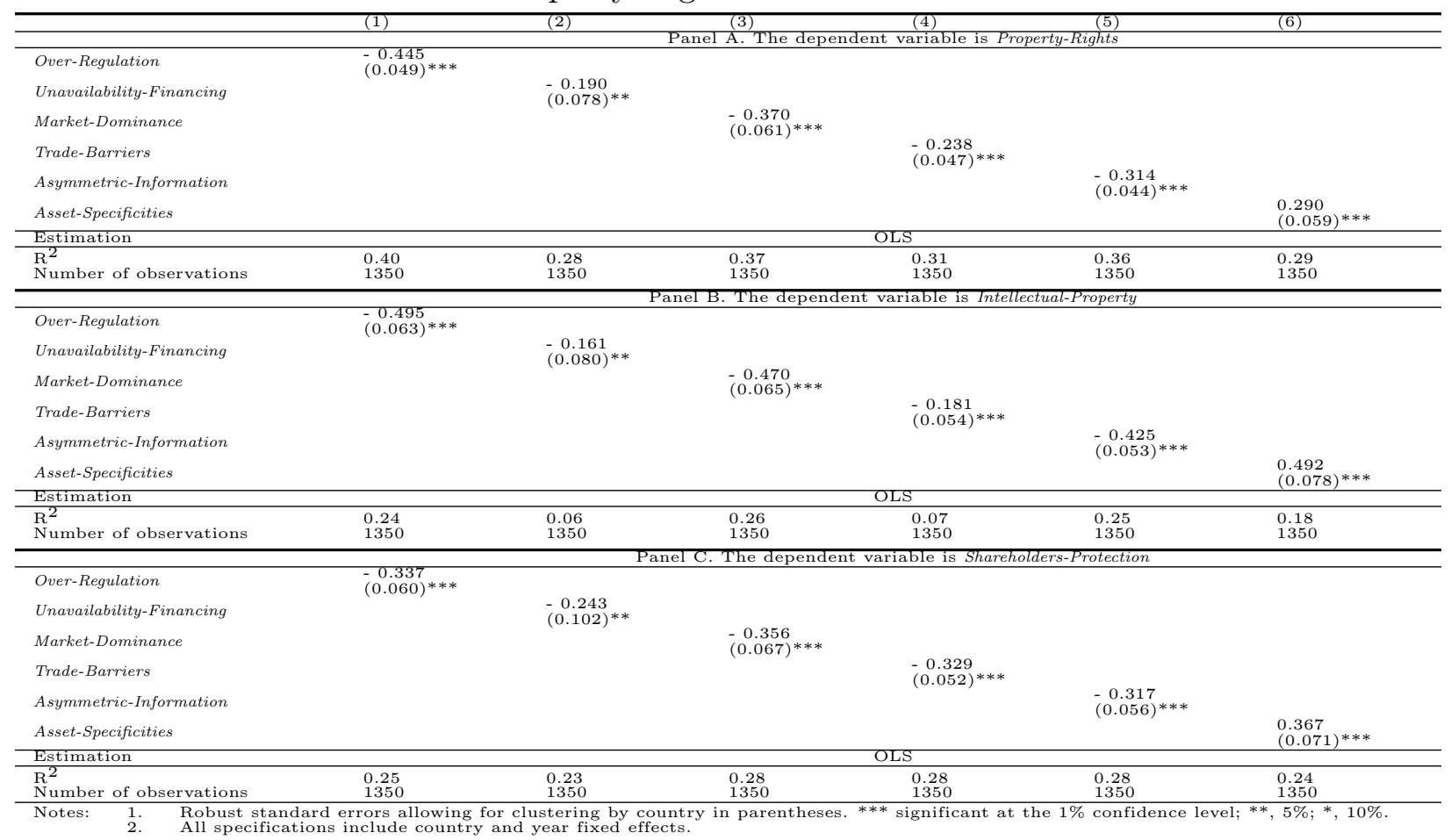

\section{Table 4: Property Rights and Transaction Costs - Controlling for Observables}

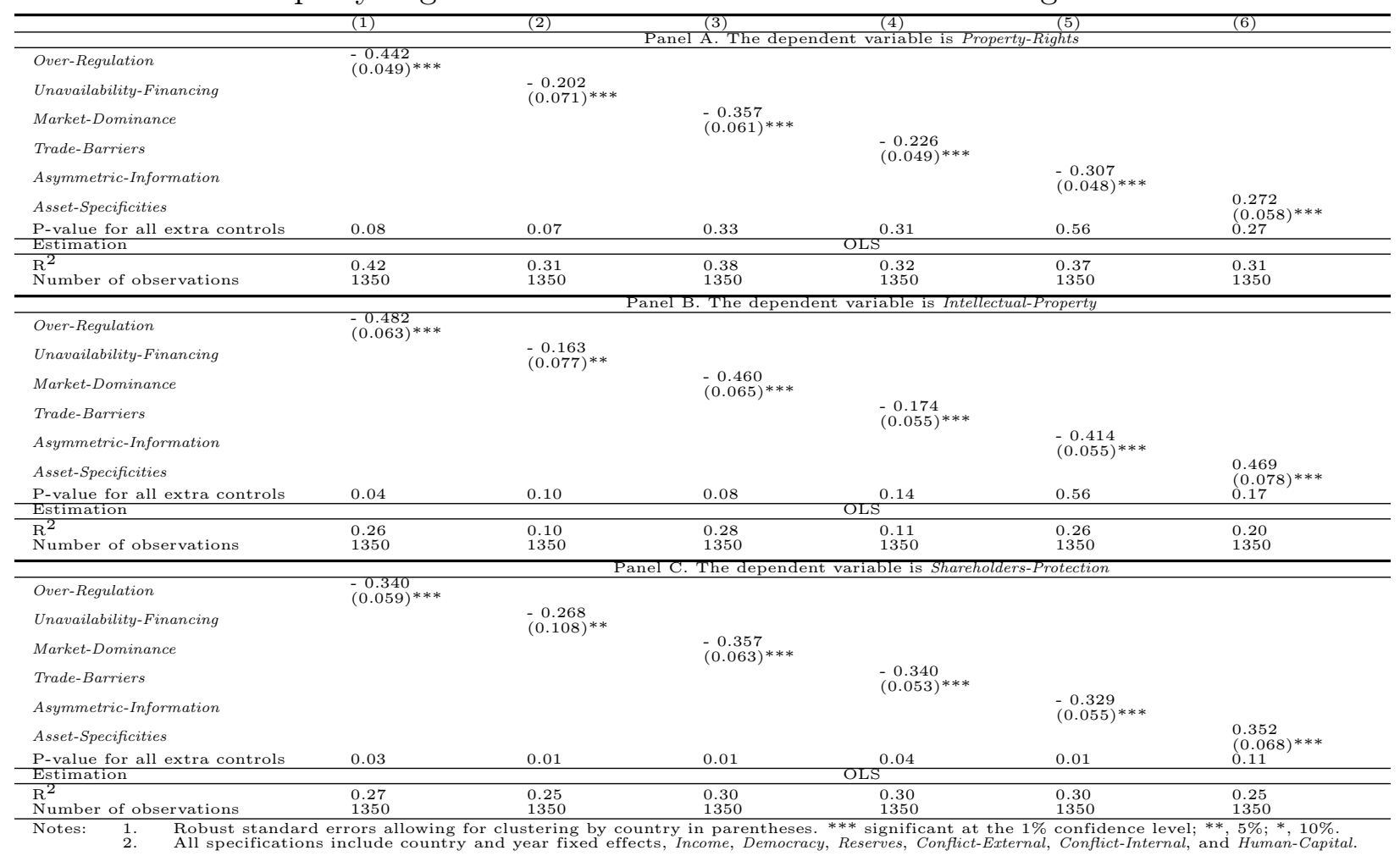




\section{Table 5: Using Selection on Observables to Assess the Bias from Unobservables}

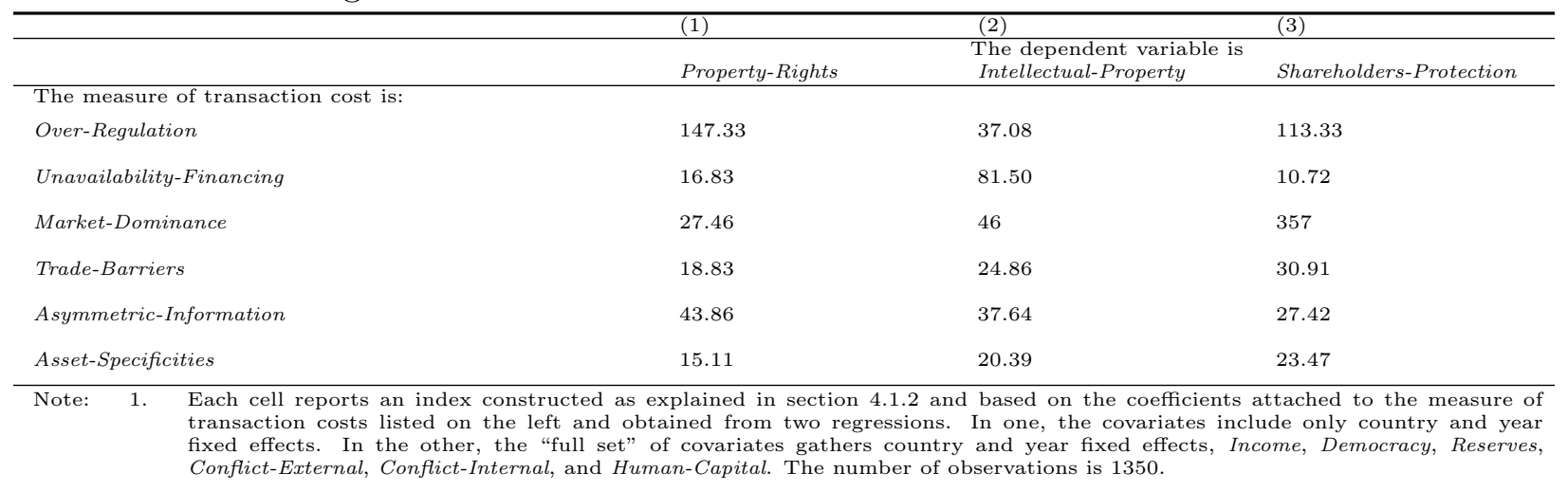

Table 6: Property Rights and Endogenous Transaction Costs

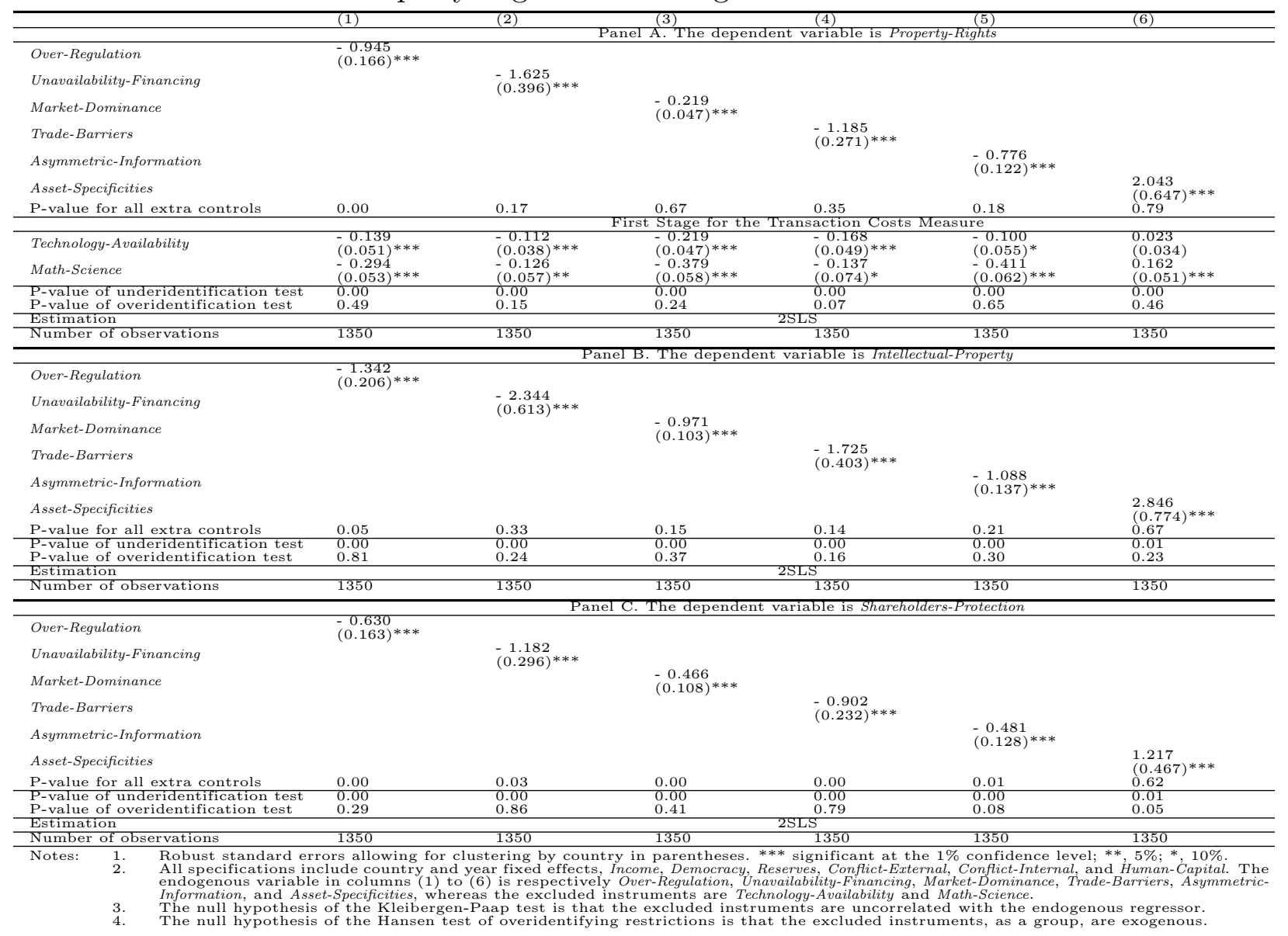




\section{APPENDIX (NOT FOR PUBLICATION)}

\section{References}

Dari-Mattiacci, Giuseppe, and Carmine Guerriero. 2017. "A Novel Dataset on Horizontal

Property Rights in 126 Jurisdictions." Data in Brief, 11: 557-561.

\section{Supplementary Tables}

Table I: Summary of Variables

\begin{tabular}{|c|c|c|c|}
\hline & Variable & Definition and Sources & Statistics \\
\hline \multirow{2}{*}{$\begin{array}{l}\text { Property } \\
\text { rights: }\end{array}$} & Adverse-Possession: & $\begin{array}{l}\text { Years needed for adverse possession by any good-faith possessor of a movable good. } \\
\text { Source: Dari-Mattiacci and Guerriero (2017). }\end{array}$ & $\begin{array}{c}9.066 \\
(10.570) \\
{[53]}\end{array}$ \\
\hline & Investors-Protection & $\begin{array}{l}\text { Index ranging between } 1 \text { and } 10 \text { and gaging the quality of both conflict of interest } \\
\text { regulation and shareholder governance. Source: World Bank, Doing Business Project } \\
2006-2015 \text {, available at http://www.doingbusiness.org/data }\end{array}$ & $\begin{array}{l}5.101 \\
(1.575) \\
{[1350]}\end{array}$ \\
\hline \multirow{5}{*}{$\begin{array}{l}\text { Transaction } \\
\text { costs: }\end{array}$} & Bribery: & $\begin{array}{l}\text { Index ranging between one and seven and rising with the extent to which making } \\
\text { bribes in connection with their daily activities is common for firms. Source: 2006- } \\
2015 \text { EOS. }\end{array}$ & $\begin{array}{c}2.902 \\
(1.198) \\
{[1350]}\end{array}$ \\
\hline & Unavailability-Loans: & $\begin{array}{l}\text { Index ranging between one and seven and rising with the difficulty to obtain a bank } \\
\text { loan with only a good business plan and no collateral. Source: 2006-2015 EOS. }\end{array}$ & $\begin{array}{l}3.995 \\
(0.874) \\
{[1350]}\end{array}$ \\
\hline & Unavailability-Equity: & $\begin{array}{l}\text { Index ranging between one and seven and rising with how difficult is it for companies } \\
\text { to raise money by issuing shares on the stock market. Source: } 2006-2015 \text { EOS. }\end{array}$ & $\begin{array}{l}3.254 \\
(1.105) \\
{[1350]}\end{array}$ \\
\hline & Market-Power: & $\begin{array}{l}\text { Index ranging between one and seven and falling with the intensity of competition } \\
\text { in the local markets. Source: 2006-2015 EOS. }\end{array}$ & $\begin{array}{l}2.165 \\
(0.667) \\
{[1350]}\end{array}$ \\
\hline & Production-Sophistication: & $\begin{array}{l}\text { Index ranging between one and seven and gaging the extent of production } \\
\text { sophistication. A value of one (seven) suggests that production uses labor-intensive } \\
\text { (sophisticated and knowledge-intensive) processes. Source: 2006-2015 EOS. }\end{array}$ & $\begin{array}{c}3.792 \\
(1.064) \\
{[1350]}\end{array}$ \\
\hline \multirow{2}{*}{$\begin{array}{l}\text { Other } \\
\text { controls: }\end{array}$} & Enforcement: & $\begin{array}{l}\text { See text. Source: United Nations, Surveys of Crime Trends and the Operations of } \\
\text { Criminal Justice Systems 2005-2015, available at https://www.unodc.org/ }\end{array}$ & $\begin{array}{c}-0.007 \\
(1.012) \\
{[740]}\end{array}$ \\
\hline & Culture: & $\begin{array}{l}\text { See text. Sources: European Value Study and World Value Survey available at } \\
\text { http://www.europeanvaluesstudy.eu/ and http://www.worldvaluessurvey.org/ }\end{array}$ & $\begin{array}{c}-0.0004 \\
(1.030) \\
{[590]}\end{array}$ \\
\hline
\end{tabular}


Table II: Property Rights and Endogenous Transaction Costs - Cross-Section

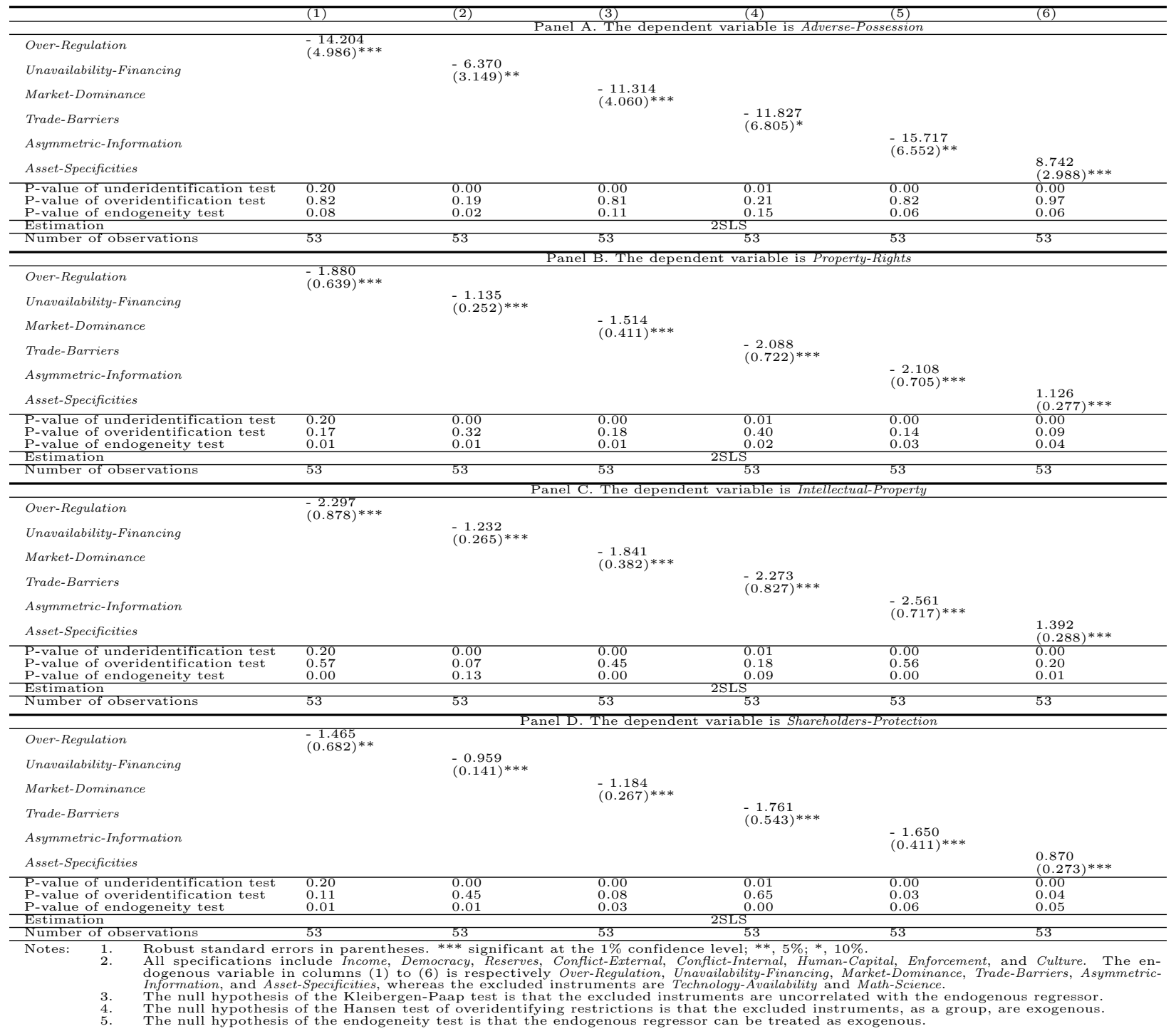

Table III: Investors Protection and Endogenous Transaction Costs

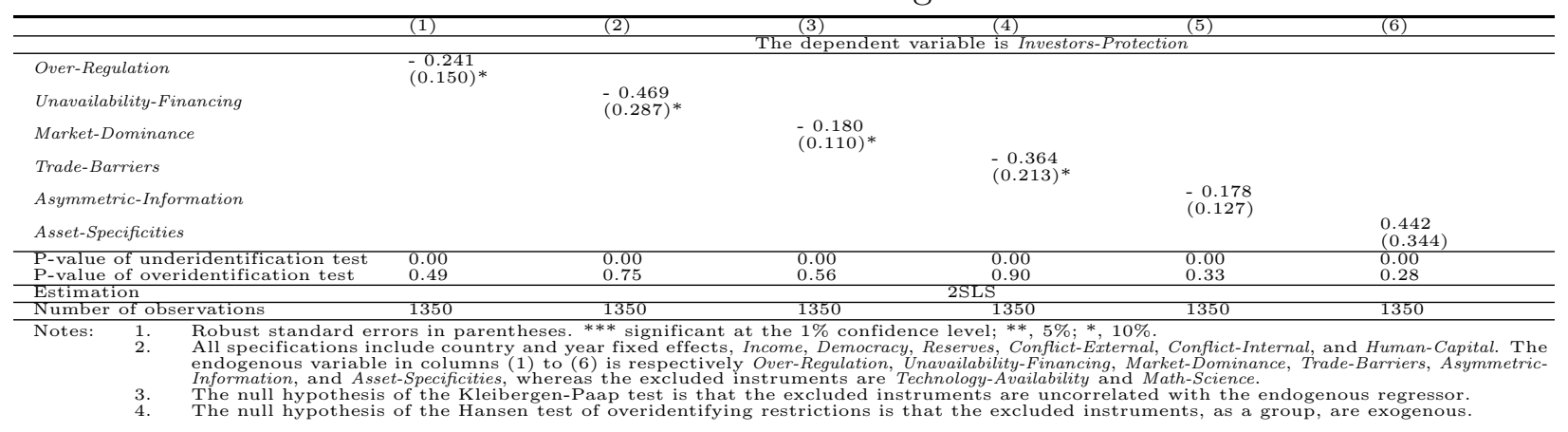


Table IV: Property Rights and Other Measures of Endogenous Transaction Costs

\begin{tabular}{|c|c|c|c|c|c|}
\hline & (1) & $(2)$ & (3) & $(4)$ & (5) \\
\hline Bribery & $\begin{array}{l}-1.427 \\
0.321 * * *\end{array}$ & & & \multirow{5}{*}{$\begin{array}{l}-0.622 \\
(0.144)^{* * *}\end{array}$} & \multirow{6}{*}{$\begin{array}{l}0.817 \\
(0.127)^{* * *} \\
0.00 \\
0.53\end{array}$} \\
\hline Unavailability-Loans & & -0.763 (2) & & & \\
\hline Unavailability-Equity & & & $\begin{array}{l}-0.617 \\
(0.175)^{* * *}\end{array}$ & & \\
\hline Market-Power & & & & & \\
\hline Production-Sophistication & & & & & \\
\hline $\begin{array}{l}\text { P-value of underidentification test } \\
\text { P-value of overidentification test }\end{array}$ & $\begin{array}{l}0.00 \\
0.60\end{array}$ & $\begin{array}{l}0.00 \\
0.07\end{array}$ & $\begin{array}{l}0.00 \\
0.00\end{array}$ & $\begin{array}{l}0.00 \\
0.00\end{array}$ & \\
\hline $\begin{array}{l}\text { Estimation } \\
\text { Number of observations }\end{array}$ & 1350 & 1350 & 2 2SLS & 1350 & 1350 \\
\hline & & Pane & ependent varie & Mlectual-Property & \\
\hline Bribery & $\begin{array}{l}-2.027 \\
(0.454) * * *\end{array}$ & & & & \\
\hline Unavailability-Loans & & $\begin{array}{l}-1.0511 * * * \\
(0.174) * * *\end{array}$ & & & \\
\hline Unavailability-Equity & & & $\begin{array}{l}-0.802 \\
(0.202)^{* * *}\end{array}$ & & \\
\hline Market-Power & & & & $\begin{array}{l}-0.937 \\
(0.173) * * *\end{array}$ & \\
\hline Production-Sophistication & & & & & $\begin{array}{l}1.159 \\
(0.123) * * *\end{array}$ \\
\hline $\begin{array}{l}\text { P-value of underidentification test } \\
\text { P-value of overidentification test }\end{array}$ & $\begin{array}{l}0.00 \\
0.82\end{array}$ & $\begin{array}{l}0.00 \\
0.02\end{array}$ & $\begin{array}{l}0.00 \\
0.00\end{array}$ & $\begin{array}{l}0.00 \\
0.00\end{array}$ & $\begin{array}{l}0.00 \\
0.81\end{array}$ \\
\hline $\begin{array}{l}\text { Estimation } \\
\text { Number of observations }\end{array}$ & 0.82 & 1350 & $2 \mathrm{SLS}$ & 0.00 & 0.81 \\
\hline & & Panel & sendent variat & holders-Protectic & \\
\hline Bribery & -0.953 & & & & \\
\hline Unavailability-Loans & & $\begin{array}{l}-0.422 \\
(0.135) * * *\end{array}$ & & & \\
\hline Unavailability-Equity & & & $\begin{array}{r}-0.216 \\
(0.164)\end{array}$ & & \\
\hline Market-Power & & & & $\begin{array}{l}-0.557 \\
(0.154 * * *\end{array}$ & \\
\hline Production-Sophistication & & & & & $\begin{array}{l}0.543 \\
(0.139) * * *\end{array}$ \\
\hline $\begin{array}{l}\text { P-value of underidentification test } \\
\text { P-value of overidentification test }\end{array}$ & $\begin{array}{l}0.00 \\
0.28\end{array}$ & $\begin{array}{l}0.00 \\
0.01\end{array}$ & $\begin{array}{l}0.00 \\
0.00\end{array}$ & $\begin{array}{l}0.00 \\
0.08\end{array}$ & $\begin{array}{l}0.00 \\
0.28 \\
\end{array}$ \\
\hline $\begin{array}{l}\text { Estimation } \\
\text { Number of observations }\end{array}$ & & 1350 & $\begin{array}{ll}2 \text { SLS } \\
1350\end{array}$ & 1350 & 1350 \\
\hline 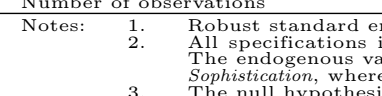 & rs allowing & $\begin{array}{l}\text { ore Techn } \\
\text { st is that } t\end{array}$ & $\begin{array}{l}\text { heses. *** sigg } \\
\text { hemocracy, Rese } \\
\text { ry, Unavailabilit } \\
\text { illity and Math } \\
\text { dinstruments }\end{array}$ & $\begin{array}{l}\text { the } 1 \% \text { confid } \\
\text { ict-External, Co } \\
\text { navailability-Equ } \\
\text { related with th }\end{array}$ & $\begin{array}{l}1 ; * *, 5 \% ; * \\
\text { aal, and Hum } \\
t-\text { Power, and } \\
\text { nous regress }\end{array}$ \\
\hline
\end{tabular}

Table V: Controlling for the Intermediation Technology

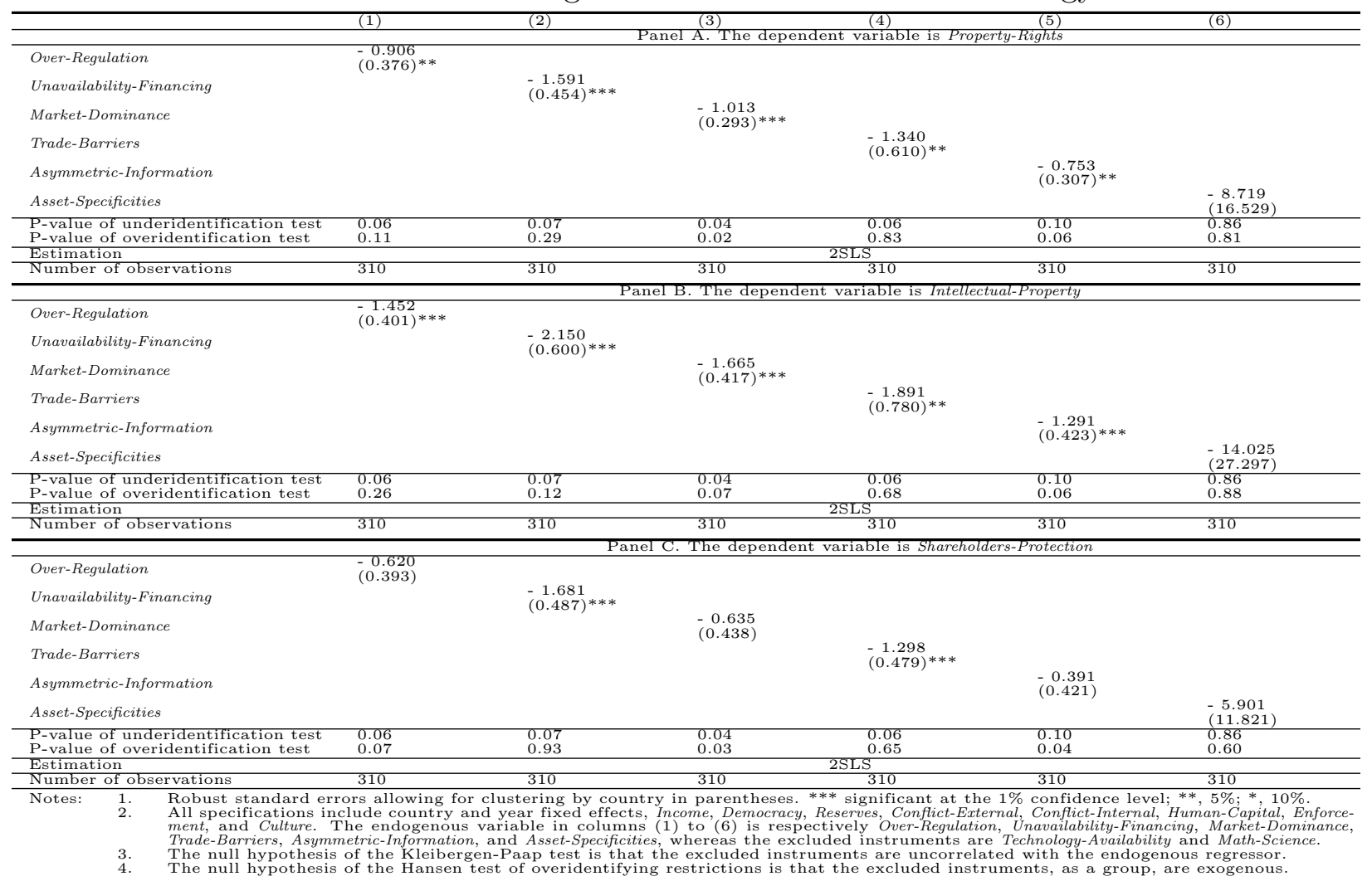




\section{Table VI: Property Rights and Endogenous Transaction Costs — Semi-reduced Forms}

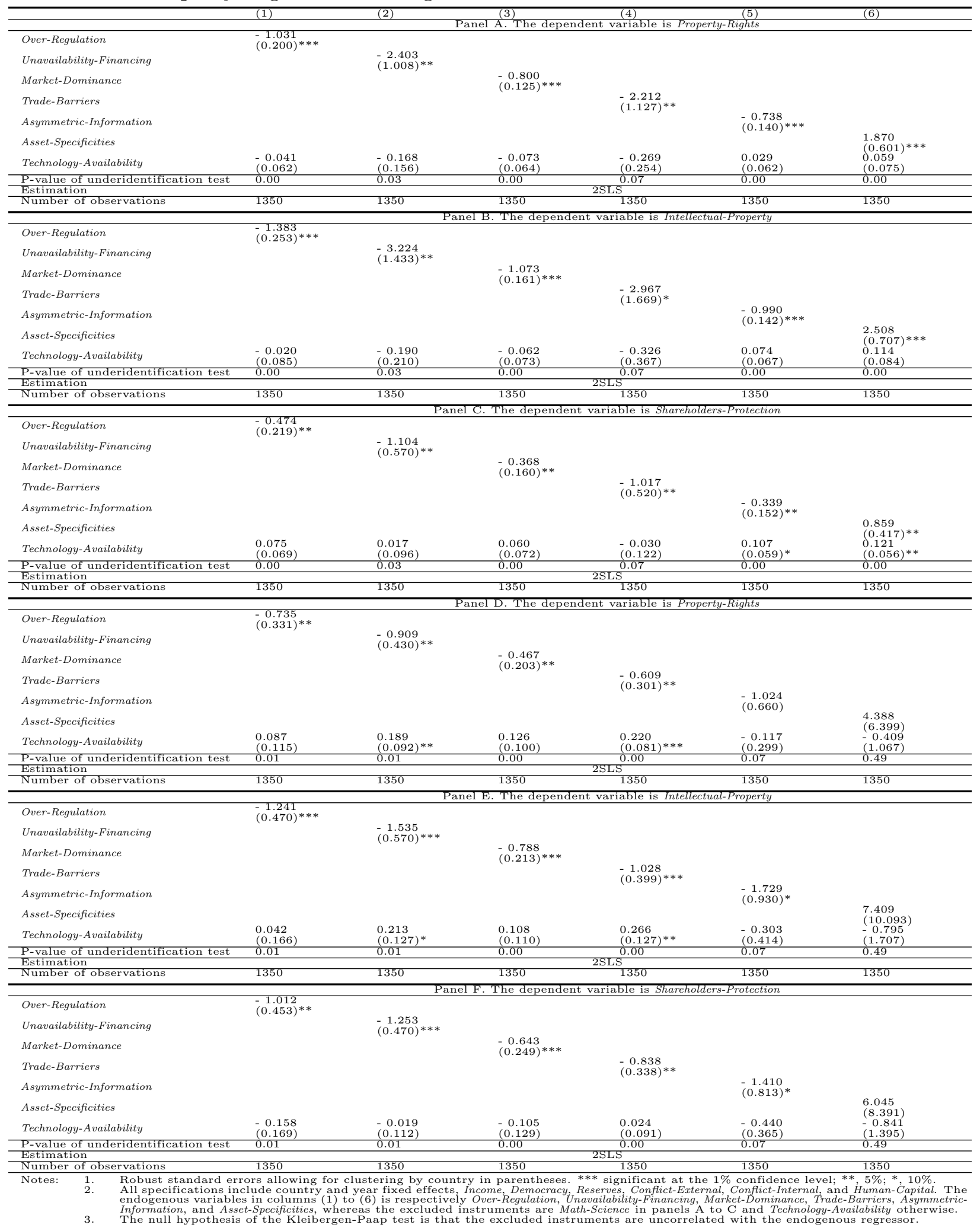




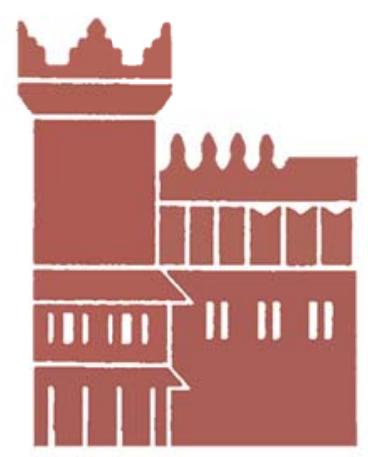

Alma Mater Studiorum - Università di Bologna DEPARTMENT OF ECONOMICS

Strada Maggiore 45

40125 Bologna - Italy

Tel. +39051 2092604

Fax +390512092664

http://www.dse.unibo.it 